\title{
Identifying the etiology and pathophysiology underlying stunting and environmental enteropathy: study protocol of the AFRIBIOTA project
}

Pascale Vonaesch ${ }^{1}$, Rindra Randremanana ${ }^{2}$, Jean-Chrysostome Gody ${ }^{3}$, Jean-Marc Collard ${ }^{4}$, Tamara Giles-Vernick ${ }^{5}$, Maria Doria ${ }^{1}$, Inès Vigan-Womas ${ }^{6}$, Pierre-Alain Rubbo ${ }^{7}$, Aurélie Etienne ${ }^{2}$, Emilson Jean Andriatahirintsoa ${ }^{8}$, Nathalie Kapel ${ }^{9}$, Eric Brown ${ }^{10}$, Kelsey E. Huus ${ }^{10}$, Darragh Duffy ${ }^{11}$, B.Brett Finlay ${ }^{10}$, Milena Hasan ${ }^{12}$, Francis Allen Hunald ${ }^{13}$, Annick Robinson ${ }^{14}$, Alexandre Manirakiza ${ }^{15}$, Laura Wegener-Parfrey ${ }^{16}$, Muriel Vray ${ }^{5}$, Philippe J. Sansonetti ${ }^{*}$ (D) for the AFRIBIOTA Investigators

\begin{abstract}
Background: Globally one out of four children under 5 years is affected by linear growth delay (stunting). This syndrome has severe long-term sequelae including increased risk of illness and mortality and delayed psychomotor development. Stunting is a syndrome that is linked to poor nutrition and repeated infections. To date, the treatment of stunted children is challenging as the underlying etiology and pathophysiological mechanisms remain elusive. We hypothesize that pediatric environmental enteropathy (PEE), a chronic inflammation of the small intestine, plays a major role in the pathophysiology of stunting, failure of nutritional interventions and diminished response to oral vaccines, potentially via changes in the composition of the pro- and eukaryotic intestinal communities. The main objective of AFRIBIOTA is to describe the intestinal dysbiosis observed in the context of stunting and to link it to PEE. Secondary objectives include the identification of the broader socio-economic environment and biological and environmental risk factors for stunting and PEE as well as the testing of a set of easy-to-use candidate biomarkers for PEE. We also assess host outcomes including mucosal and systemic immunity and psychomotor development. This article describes the rationale and study protocol of the AFRIBIOTA project.
\end{abstract}

Methods: AFRIBIOTA is a case-control study for stunting recruiting children in Bangui, Central African Republic and in Antananarivo, Madagascar. In each country, 460 children aged 2-5 years with no overt signs of gastrointestinal disease are recruited (260 with no growth delay, 100 moderately stunted and 100 severely stunted). We compare the intestinal microbiota composition (gastric and small intestinal aspirates; feces), the mucosal and systemic immune status and the psychomotor development of children with stunting and/or PEE compared to non-stunted controls. We also perform anthropological and epidemiological investigations of the children's broader living conditions and assess risk factors using a standardized questionnaire.

Discussion: To date, the pathophysiology and risk factors of stunting and PEE have been insufficiently investigated. AFRIBIOTA will add new insights into the pathophysiology underlying stunting and PEE and in doing so will enable implementation of new biomarkers and design of evidence-based treatment strategies for these two syndromes.

Keywords: Stunting, Pediatric environmental enteropathy, Madagascar, Central African Republic, Microbiota, Immunology, Medical anthropology, Child development, Biomarkers, Risk factors

\footnotetext{
* Correspondence: philippe.sansonetti@pasteur.fr

'Unité de Pathogénie Microbienne Moléculaire, Institut Pasteur, 28 Rue du

Dr. Roux, 75015 Paris, France

Full list of author information is available at the end of the article
}

(C) The Author(s). 2018 Open Access This article is distributed under the terms of the Creative Commons Attribution 4.0 International License (http://creativecommons.org/licenses/by/4.0/), which permits unrestricted use, distribution, and reproduction in any medium, provided you give appropriate credit to the original author(s) and the source, provide a link to the Creative Commons license, and indicate if changes were made. The Creative Commons Public Domain Dedication waiver (http://creativecommons.org/publicdomain/zero/1.0/) applies to the data made available in this article, unless otherwise stated. 


\section{Background}

Stunting (linear growth delay) remains one of the most pressing global health problems with roughly one out of four (155 million) children under 5 years of age affected (Global Nutrition report 2017). Stunting is defined as a height-for-age $\mathrm{z}$-score $\leq-2 \mathrm{SD}$ of the median height of the WHO reference population [1, 2]. In Central African Republic (CAR) and Madagascar, where AFRIBIOTA is based, the percentage of stunted children under 5 years is alarmingly high: $47 \%$ of Malagasy children [3] and 41$43 \%$ of CAR children (World Bank and Global Nutrition report, data 2010) experience stunted growth, making them two of the most affected countries in the world. Undernutrition in early childhood leads to diminished physical and mental development $[4,5]$, producing poor school performance and, on average, $22 \%$ less income in adulthood (Levels and Trends in Child Malnutrition, WHO, UNICEF, World Bank, 2012; [3]). Undernutrition is thus a major driver of poverty. Despite decades-long efforts to treat and reduce undernutrition through nutritional rehabilitation, these programs have been less efficacious than expected due to the persistent vicious cycle between undernutrition and infection $[6,7]$. While the prevalence of stunting has slightly decreased globally in the past two decades, it has only marginally decreased in Sub-Saharan Africa, and the actual number of affected children has increased [8].

The current potential causes of stunting range from inadequate food to poor hygiene and repeated infections [6]. Stunting is a complex entity that may reflect several etiologies, particularly a poor, unbalanced diet and insufficient vitamin/micronutrient intake. It also involves social factors, including family's resources and configuration, as well as the broader political and economic conditions in which children live [9].

To date, although evidence about social and other risk factors that contribute to stunting exists, its pathophysiological mechanisms remain largely elusive. As a consequence, there is still no proper intervention to cure stunting, and the most effective interventions correct for at best one third of the observed linear growth delay [10]. In recent years, accumulating evidence has shown that a chronic, inflammatory syndrome of the small intestine, called pediatric environmental enteropathy (PEE), may play a major role in this syndrome. [11-14]. PEE (also called tropical enteropathy or environmental enteric dysfunction) is a subclinical condition generally thought to be caused by constant fecal-oral contamination [15-19] resulting in increased permeability of the small intestine and influx of immune cells into the gut epithelium [20]. This chronic inflammation leads to characteristic shortening of the villi, diminishing the absorptive surface of the intestine (reviewed in [20-22]). It is believed that stunting and PEE are two intertwined syndromes, leading to a vicious cycle exacerbated over time [23-29]. Histopathological analysis conducted on duodenal biopsies, and microbiological studies conducted on duodenal aspirates of infants and children affected by PEE have revealed three major components supporting the current pathophysiological hypothesis [30]: intestinal atrophy through villi blunting, inflammatory infiltration into both the epithelium and the lamina propria, and outgrowth of pro-inflammatory Enterobacteriae and bona fide enteric pathogens [31]. Hence two, likely related, etiological options may explain PEE: (i) a succession of enteric infections, or (ii) a dysbiotic microbiota involving a sustained oral acquisition of fecal organisms that colonize the duodeno-jejunum, thereby creating small intestinal bacterial overgrowth (SIBO) comprised of a pro-inflammatory microbial community. This microbiota dysbiosis results in an ecosystem that cannot maintain the major parameters of gut homeostasis and function in a part of the intestine that is vital for digestion and nutrient absorption. Both scenarios might take place either in an intestine weakened by undernutrition, or might lead themselves to undernutrition, thereby initiating the vicious cycle.

The MAL-ED (Malnutrition and Early Disease) consortium addressed the first hypothesis, looking for (asymptomatic) infections leading to subsequent growth delays. They showed that intestinal inflammation and growth delay among infants in eight developing countries were associated with entero-invasive/mucosa-disrupting enteropathogens [32]. A recent study in Bangladesh concluded that enteric infections, especially of Shigella and enterotoxic E. coli (ETEC), were associated with PEE and stunting in the first 2 years of life [33]. Two other studies found entero-aggregative E. coli (EAEC) to be associated with markers of PEE (gut inflammation) and linear growth delay [34, 35].

The second hypothesis, stating that a dysbiosis, rather than actual infection, might lead to PEE, remains unaddressed in humans. It is nonetheless supported by several observations. Peace Corps volunteers diagnosed with EE took up to a year to recover from the syndrome, even once exposed to improved food and water hygiene upon returning to the US $[36,37]$. This also implies that affected children cannot simply be fed a nutritious diet to recover from the syndrome. The observed "imprinting" stresses the significance of long-lasting effects. "Imprinting" could be mediated by specific, pro-inflammatory members of the microbiota, which remain in the microbial community even after dislocation to better hygienic conditions. Alternatively, this phenotype could be due to epigenetic imprinting, leading to changes in the general gut homeostasis. The causative role of given microbes in inducing and sustaining undernutrition is supported by two studies in mice, which reproduced the main hallmarks of 
PEE by chronic undernutrition and gavage with a given set of pathobionts. Further, it was possible to transfer the PEE phenotype by inoculating germ-free mice with feces of affected animals. Likewise, feces from stunted children inoculated into germ-free mice led to stunting in the recipient mice $[26,38,39]$. Human data for this second hypothesis is therefore urgently needed as to assess the pathophysiological mechanisms underlying these interactions in greater detail and to identify potential interventions.

In AFRIBIOTA, we focus on children falling under the second etiology: children with or without linear growth delay in apparently good health at the time point of inclusion. We hypothesize that stunting and PEE are caused by changes in the gut ecosystem, first and foremost the bacterial microbiota but likely also to changes induced in the pool of bile acids, the eukaryome, as well as the mucosal immune system.

PEE was described for the first time in the late 1960s, based on abnormal histology of the small intestine [40, 41]. Several other studies were performed in the following decades to explore other biomarkers of the disease [42-50]. Nevertheless, to date, characterizing PEE in the absence of biopsies showing PEE blunting and immune cell infiltration remains a challenge. Gut permeability, measured through the lactulose/lactitol-mannitol test, is the current reference test. However, gut permeability is an unspecific condition, occurring under different clinical circumstances, and with potentially diverse etiologies including infection. The test's specificity is thus highly debated, and its value must be contextually interpreted. Furthermore, the test requires that children fast overnight, after which their urine needs to be collected over $5 \mathrm{~h}$ and analyzed using mass spectrometry. Therefore, this analysis remains difficult to perform in low-income settings, and expensive to conduct on a large scale.

For this reason, few PEE studies have been conducted. An easy to use, inexpensive, specific, and sensitive diagnostic test for PEE is therefore urgently needed. In the last 2 years, several studies have reported analyses of biomarkers for PEE [51, 52]. The rational of the choice of biomarkers is often based on the fact that PEE is clinically similar to inflammatory bowel disease (IBD), therefore some of the markers for IBD might also be valid for PEE [53, 54]. From the first studies performed, a general consensus emerged on the fact that (systemic) inflammation appears to be most associated with linear growth deficit $[51,52]$. However, more studies are needed to validate these first results in other contexts and other age groups.

In recent years, certain studies have addressed risk factors associated with PEE. The main risk factors found were nutritional status, exposure to pathogens, illness, socioeconomic status and feeding practices [32]. Further, geophagy [16] and mouthing of soil-contaminated objects [15] as well as animal exposure and caregiver hygiene [19] were also associated with an increased risk for PEE. The most important factors associated with PEE can be conceptualized by: (1) underlying and contributing factors, which are mainly of social origin; (2) biological mechanisms leading to the pathophysiological changes observed in the small intestine; and (3) pathophysiological outcomes of these small intestinal changes (Fig. 1). Many of the factors underlying PEE and stunting are tightly linked, such as parasite burden, infection, socioeconomic status and access to health care. Therefore, it is crucial to collect as much metadata as possible

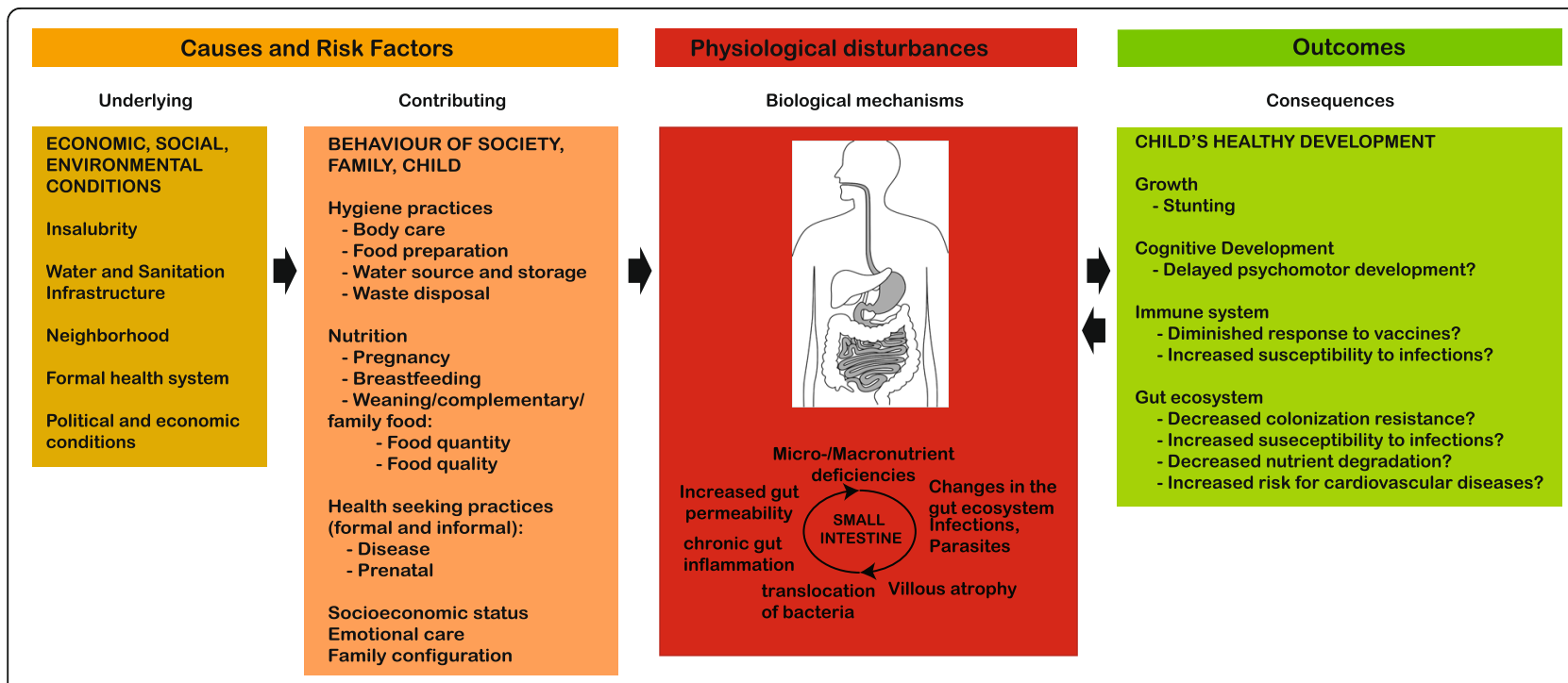

Fig. 1 Scheme depicting the different entities underlying or being affected by pediatric environmental enteropathy (PEE). Underlying causes are colored in orange, physiological changes in red and consequences in green 
for each child to correct for these factors and analyze the different influences independently from each other. Only a tightly controlled study group will allow correction for a maximum of confounding factors and truly shed light on the pathophysiological associations observed upon PEE. To this purpose, in AFRIBIOTA, we decided to include a larger number of children rather than performing a longitudinal study on fewer children.

In addition to its correlation with stunting, PEE is also linked to other long-term sequelae, including psychomotor delay, diminished oral vaccine performance [55] and increased risk of cardiovascular diseases later in life [47]. The estimated prevalence of PEE is greater than $75 \%$ in the most affected regions [11, 13, 56, 57]. Considering its very high prevalence in low-income countries, PEE now ranks among health priorities for which efficient prevention/treatment should significantly improve childhood health and future life quality.

Several consortia have begun to investigate PEE in the previous decade $[49,58,59]$. AFRIBIOTA departs from these investigations in several ways, and is a study uniquely designed to fill in existing knowledge gaps in the field. By definition, PEE is a small intestinal disease. AFRIBIOTA collects duodenal samples that are precious for they likely contain the putative microbial biomarkers that will allow a better understanding of the ecology of affected children's small intestines. The microbiota differs greatly between the different compartments of the gastrointestinal tract [60-62], and it is therefore important to define small intestinal microbiota present in the context of PEE and stunting. Secondly, different candidate biomarkers are simultaneously measured in a group of almost 1000 children, to better delineate the components of PEE. This will allow a comparison of the different markers and to develop models to design a multi-parametric composite test to discriminate PEE from other gastrointestinal disorders. Finally, AFRIBIOTA combines different disciplines and approaches to understand the conditions facilitating and sustaining PEE and growth delay. These approaches will yield detailed evidence concerning each child, allowing screening for associations between social and biological factors.

The main objective of the AFRIBIOTA project is to shed light on the interactions between dysbiosis and stunting/PEE in children between the age of two and 5 years.

Secondary objectives include i) testing a panel of candidate biomarkers for PEE, ii) investigating the broader social environment and epidemiological risk factors for stunting and PEE and iii) describing possible associated pathophysiological changes in the mucosal and systemic immune system as well as delayed psychomotor development in children.
In conclusion, AFRBIOTA promises to add valuable insight to the developing picture of the pathophysiology underlying stunting and PEE, and to extend existing efforts to comprehend these two syndromes.

\section{Methods/Design \\ General study design/recruitment}

AFRIBIOTA is a matched case-control study for stunting. In order to correct for study-site specific variables (ex: climatic factors, food habits, overall genetic make-up of the population), we opted to perform the study in two distinct study countries (Madagascar and Central African Republic). Three different categories of children aged 2-5 years are enrolled in the study: severely and moderately stunted children (100 of each group/ country) and children with no growth delay (260/country). Severe stunting is defined as a height-for-age $z$-score $\leq-3 \mathrm{SD}$, moderate stunting as height-for-age z-score between -3SD and -2SD of the median height of the WHO reference population $[1,2]$. Control children are children without stunting (height-for-age z-score $>2 S D$ ). Stunted and control children are matched according to age (24-35 months, 36-47 months and 48-60 months), gender and neighborhood (same neighborhood or adjacent neighborhood as based on the official maps distributed by the respective Ministries) and season of inclusion (dry or wet season). As PEE cannot be measured in the field with the diagnostic tests currently available, we hypothesized that most stunted children display PEE while most of the non-stunted children would display the syndrome at a lower level of severity or not at all. Stunting was therefore taken as a proxy for PEE. Recruitment started in December 2016 in Antananarivo and in January 2017 in Bangui and is currently ongoing. Recruitment should be completed by summer 2018. The study includes a total of 920 children.

\section{Inclusion and non-inclusion criteria}

We applied the following inclusion and exclusion criteria: i) children being between 24 and 60 months old and capable of participating in the different tests and clinical sampling; ii) not showing any of the following exclusion criteria: severe acute illness, acute malnutrition or enteropathy, including HIV-associated enteropathy or severe diarrhea and iii) not under recent antibiotic treatment or renutrition regimens (to avoid bias in composition of the dysbiosis associated with stunting and/or PEE, as both of these interventions were shown to lead to severe changes in the microbiota composition [63-67]) (Table 1).

\section{Recruitment procedures Madagascar}

In Antananarivo, the recruitment is community- (90\%) and hospital-based (10\%). We expected challenges with 
Table 1 Inclusion and exclusion criteria

\begin{tabular}{ll}
\hline Inclusion criteria & Exclusion criteria \\
\hline - Children between the age of 24 and 60 months & - HIV positive test at inclusion \\
- General health status allowing for the tests to be performed & - Signs of respiratory distress $(\geq 40 /$ min $)$ \\
& - Fever $\left(\geq 38.5^{\circ} \mathrm{C}\right)$ \\
& - Infectious diarrhoea with mucus or blood \\
& - Rentibiotics taken in the 2 weeks prior to inclusion \\
& - Septic shock \\
& - Vomiting \\
& - Acute malnutrition $(W H Z \leq-2)$ \\
\hline
\end{tabular}

acceptance by the parents on performing aspirations on awake children. Therefore, hospitalized children were included to facilitate duodenal aspirations, as they could be performed during surgical interventions when the child is under narcotics. Nevertheless, so far, all aspirations were performed on awake children and, thanks to a detailed and complete information package delivered by the caregivers, no issues arose concerning acceptability of the procedure.

Community recruitment is performed in Ankasina and Andranomanalina Isotry, two of the poorest neighborhoods of Antananarivo, as well as their surrounding neighborhoods. Families are informed about the study by community health workers and sent to a weekly recruitment event at the community health center of the respective neighborhood where they are measured, inclusion and exclusion criteria checked, and appointments are scheduled for the different tests (community-recruited children). Children who seek care in the Centre Hospitalo-Universitaire Mère Enfant de Tsaralalàna (CHUMET), in the Centre Hospitalo-Universitaire Joseph Ravoahangy Andrianavalona (CHU-JRA) and in the Centre de Santé Maternelle et Infantile de Tsaralalana (CSMI) and meet the inclusion and exclusion criteria are also invited to participate in the study (hospital-recruited children).

\section{CAR}

In Bangui, all recruitments are conducted in the community. Children are recruited in three districts (6th, 7th and 8th arrondissement), randomly selected among the 14 districts of Bangui. Community health workers approach families, inform them about the study, and send them for inclusion to the arrondissement health center, where recruitment sessions take place every 3 weeks (Fig. 2).

\section{Variables collected}

\section{Anthropometric measurements}

Height is measured to the nearest $0.1 \mathrm{~cm}$ in a standing position using collapsible height boards (Antananarivo: ShorrBoard ${ }^{\circ}$ Infant/Child/Adult Measuring Board, Maryland, USA; Bangui: height board provided by UNICEF); weight is measured to the nearest $100 \mathrm{~g}$ using a weighing scale (Antananarivo: KERN, ref. MGB
150 K100, Antananarivo, Madagascar and EKS, Inter-équipement Madagascar; Bangui: weighting scale provided by UNICEF). Head circumference is measured around the widest possible circumference to the nearest $0.1 \mathrm{~cm}$ using a flexible measuring rod. Mid-upper arm circumference (MUAC) is measured using commercial MUAC tape (provided by UNICEF) as follows: first, the tip of the shoulder and the tip of the elbow are determined and distance is measured. The mid-point between these two points is marked and the MUAC tape is applied. Arm circumference is measured to the nearest $0.1 \mathrm{~cm}$.

\section{Biological measurements and tests performed}

We measure different interacting entities that might play a role in the pathophysiology of child stunting and PEE (Fig. 3). They include the pro- and eukaryotic microbial community in the small intestine as well as in gastric aspirates and feces; gut atrophy; the mucosal and systemic immune response; micronutrient deficiencies; asymptomatic enteropathogens and parasite carriage; gut leakiness and atrophy and bacterial translocation; and the micro- and macro-environment of the child. For each child, feces, urine and blood are collected. For stunted children (200 children/country), we also collect gastric and duodenal aspirates. We apply both culture techniques and NGS (16S, 18S, ITS amplicon sequencing, metagenomics) to determine the community structure of the small intestinal aspirates, hence generating unprecedented data about the small intestinal community structure in children living in low-income countries. We also assess the microbial composition of feces using NGS and investigate the IgA-targeted fraction of the microbiota as to have a detailed picture of the immunogenic bacteria. Furthermore, we assess for asymptomatic pathogen carriage using GPCR targeted against the most prevalent enteropathogens and assess for the presence of parasites using conventional microscopy techniques (direct examination, Kato-Katz and MIF).

To analyze the gut ecosystem in more detail, we also describe the pool of bile acids in the duodenum and feces using targeted mass-spectrometry, describe the pool of cytokines and chemokines using a 


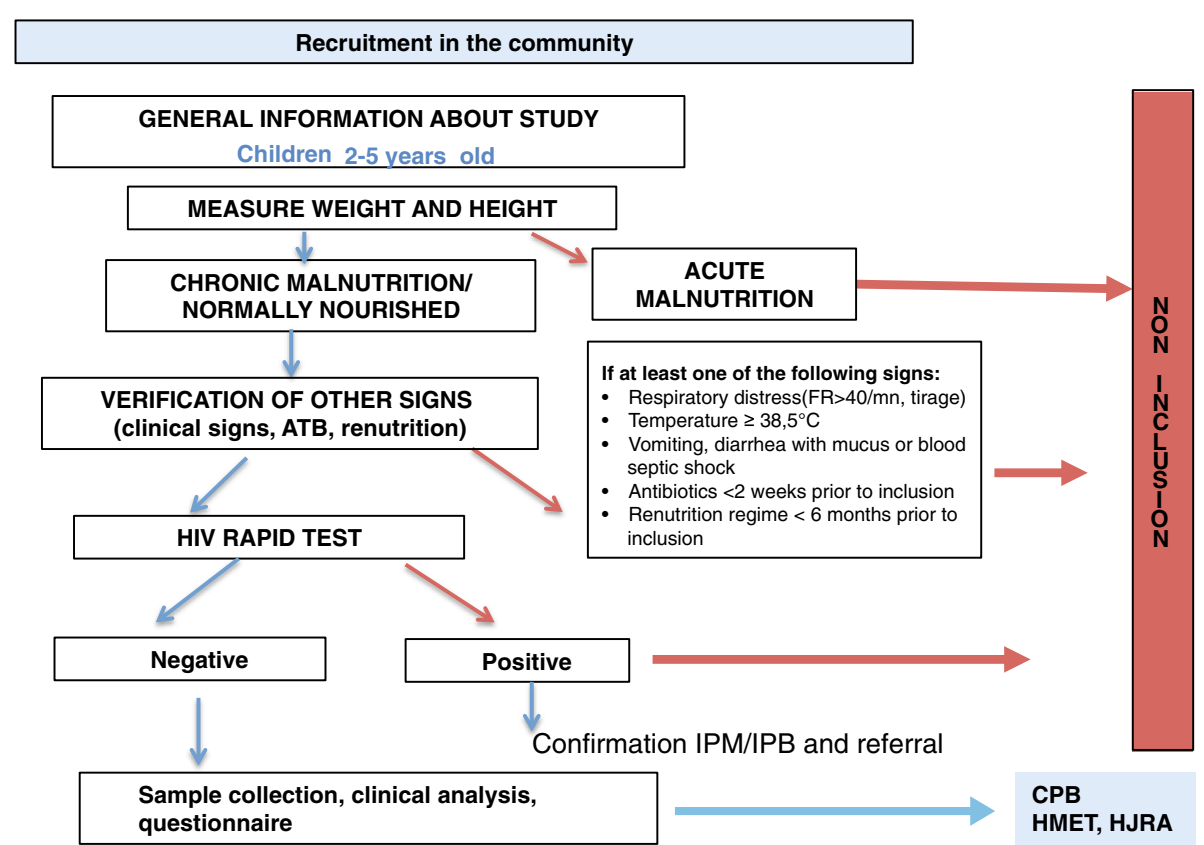

Fig. 2 Recruitment Schema of the AFRIBIOTA project

commercially available panel of 30 cytokines/chemokines/growth factors (Invitrogen; Luminex MagPix technology) as well as a commercial Luminex Assay against the different subtypes of Immunoglobulins (Biorad). The systemic immune system is analyzed using 8-color flow cytometry and a panel of pre-established antibody sets [68] to quantify the different immune cell populations, the same 30-plex kit for cytokines/chemokines/ growth factors also used on intestinal samples as well as an in vitro stimulation system to assess for immune responses against given stimuli, the TruCulture technique [69] (see Table 3 for a detailed description of the different aspects addressed).

We integrate changes in the microbiota (bacteria, eukaryotes, asymptomatic pathogen carriage) and the bile acid pool and correlate it with changes in the mucosal and peripheral immune system. Further, we analyze if the permeability of the gut in these children leads to translocation of bacteria into the bloodstream and could therefore lead to the chronic inflammation observed.

\section{Developing a better diagnostic test for pediatric environmental enteropathy}

The current gold standard diagnostic test for PEE, the lactitol-mannitol test, requires resources and technical knowledge that are frequently unavailable in resource-poor settings. Hence, to date, only limited epidemiological surveys could be performed.

In order to identify novel biomarkers and compare different tests with the reference test for PEE, the lactitol-mannitol test, a set of nine different candidate biomarkers/biomarker groups reflecting different aspects of the syndrome will be analyzed. The candidate biomarkers describe i) gut permeability, ii) mucosal inflammation, iii) systemic inflammation, iv) activation of the adaptive immune system (as reflected by the production of immunoglobulins), v) gut atrophy, vi) bacterial translocation vii) small intestinal bacterial overgrowth (SIBO), viii) specific taxa of the fecal microbiota (including pathogenic or non pathogenic bacteria, viruses and eukaryotes) and ix) specific bile acid profiles. The choice of the respective candidate biomarkers is summarized in Fig. 4 and Table 2 and detailed below.

Gut permeability Gut permeability is measured using the lactitol-mannitol test [70]. Lactitol and mannitol are both non-metabolized sugars and are secreted unchanged in the urine after absorption. Their levels reflect the permeability and the absorptive capacity of the intestine, respectively. It is the current reference test for PEE $[11,32,52,71,72]$.

Systemic inflammation The presence of a systemic inflammatory response is analyzed by blood dosage of the inflammatory marker C-reactive protein (CRP). CRP is an acute-phase protein that is quickly up-regulated and expressed in response to a variety of viral, bacterial and fungal infections as well as other non-infectious inflammatory states. 


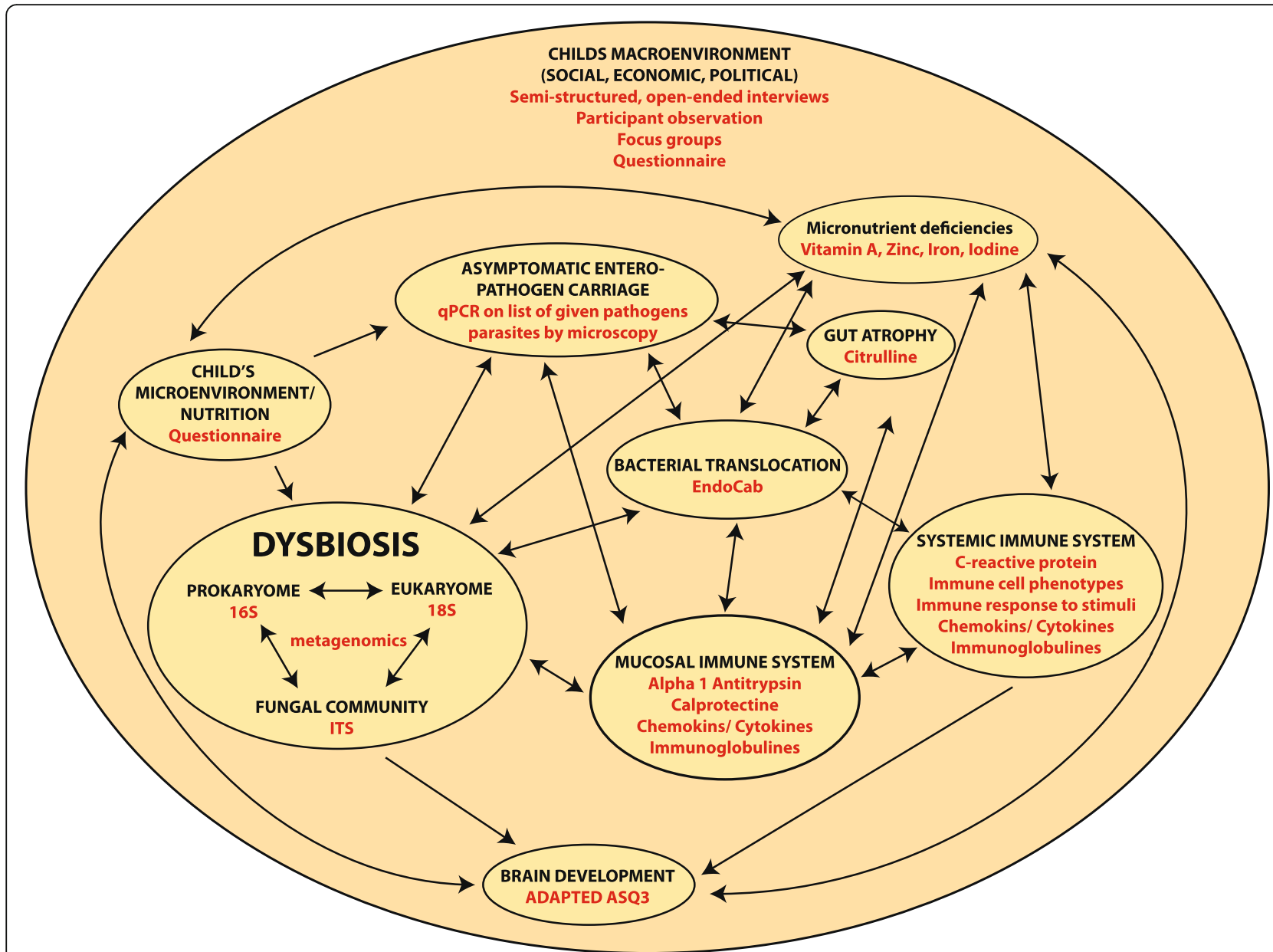

Fig. 3 Framework of the different interacting entities being associated with stunting and pediatric environmental enteropathy (PEE). Data collected for each entity in the context of the AFRIBIOTA project is indicated in red. Interactions in between the different entities are indicated with arrows. The child's macro-environment is influencing all other entities

Local inflammatory response in the gut The local inflammatory response in feces (all children) and in gastric and duodenal aspirates (stunted children only) is analyzed by dosing two different inflammatory markers: alpha1-antitrypsin and calprotectin. Alpha1-antitrypsin is released during an inflammatory state by leucocytes. Calprotectin is secreted by neutrophils and has been shown previously to be a valid biomarker for intestinal inflammation, for example in the context of inflammatory bowel disease [54]. Both markers have also been used as biomarkers in recent studies on PEE [52] and have been shown to be associated with subsequent linear growth delay.

Immunoglobulin levels (adaptive immune response) An important quantity of immunoglobulins (Ig), especially IgA, but also IgM is secreted every day in the intestinal lumen where it contributes to regulate the microbiota. An imbalance in the levels of Igs can lead to dysbiosis (reviewed in [73]). Bacterial overgrowth can also enhance secretion of IgG into the gut lumen (reviewed in [41]) and can induce a higher secretion of IgG into the blood, reflecting to some extent the permeability of the intestine. It has been previously described that in the context of undernutrition, IgG concentrations in the blood are enhanced while IgA concentrations in the gut (feces) are diminished [74]. It has also been described that Vitamin A and Vitamin D deficiencies lead to a diminished production of IgA in response to different viruses (reviewed in [43]). PEE leads at the same time to undernutrition and malabsorption resulting in diminished levels of different vitamins and trace elements [75]. We therefore hypothesize that the general levels of immunoglobulins might be affected by PEE.

Intestinal atrophy (villous abrasion) The mass of enterocytes, hence the degree of intestinal atrophy, can be measured by dosage of blood citrulline as this amino 
Biomarker analysis

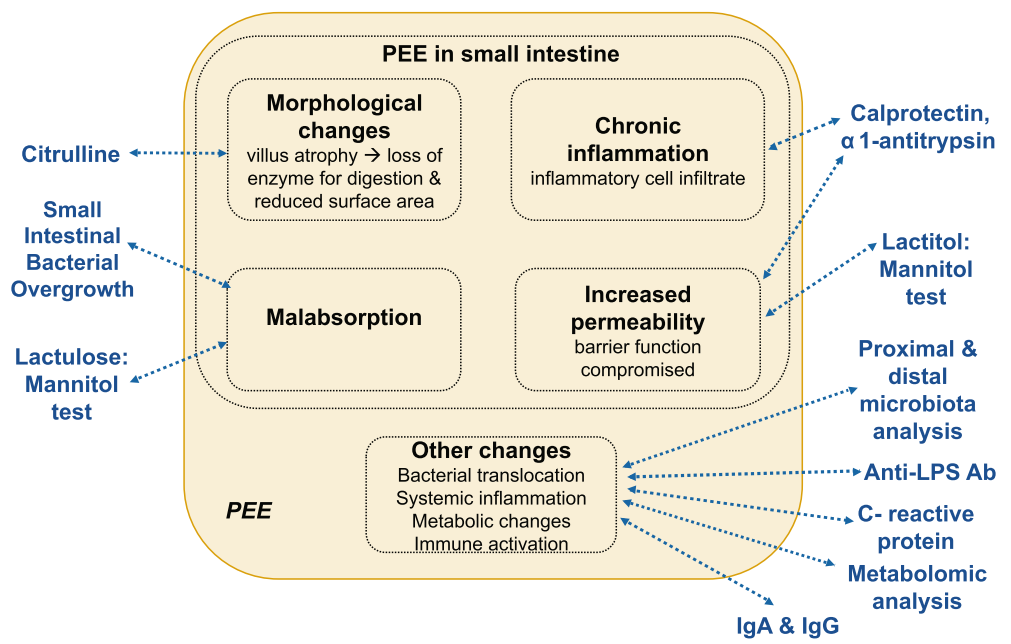

Fig. 4 Schema of the biomarker analysis performed in AFRIBIOTA. Features assessed are indicated in black, measurements performed within the context of AFRIBIOTA in blue

acid is only secreted by enterocytes. Indeed, seric citrulline levels were able to correctly predict the enterocyte mass in the context of HIV-induced enteropathy [76]. Citrulline is therefore a good substitute for histological scoring of villous length in biopsies [76-78]. In a recent study, citrulline levels have also been shown to be associated with subsequent linear growth delay [52]. Since PEE is characterized by villous atrophy, citrulline levels may be an easy to measure, reliable marker of PEE.

Bacterial translocation (circulating LPS) Several studies have assessed circulating LPS as a biomarker for PEE. While some studies showed a clear association between circulating anti-LPS antibodies and gut leakiness/linear growth delay [46, 52, 79, 80] others did not [81].
Bacterial translocation being a plausible outcome of the pathophysiology described so far for PEE, we include the endotoxin core antibody (EndoCAb ${ }^{\circ}$ test, Hycult Biotech, Uden, The Netherlands) in the panel of biomarkers to be tested.

Small Intestinal bacterial overgrowth (SIBO) PEE and undernutrition have been associated with small intestinal bacterial overgrowth [50, 82, 83]. SIBO might therefore be a good biomarker for PEE. SIBO can be measured either by the hydrogen breath test $[84,85]$ or by direct plating of duodenal aspirates [86]. In AFRIBIOTA, we opted to use the plating method to simultaneously evaluate both the presence of SIBO, and its microbial composition.

Table 2 Candidate biomarkers for environmental enteropathy

\begin{tabular}{lll}
\hline Candidate biomarkers & Pathophysiological change measured & Sample type needed for analysis \\
\hline Lactitol-mannitol test & Intestinal permeability & Urine \\
Citrulline & Villous atrophy & Bltered intestinal barrier \\
a anti-trypsin & Mucosal inflammation & Faeces \\
Calprotectin & Systemic inflammation & Faeces \\
C reactive protein (CRP) & Bacterial leakage into the systemic & Blood \\
Endotoxine (circulating LPS) & circuit (intestinal permeability) & Faeces \\
Immunoglobulines & Adaptive immune response & Blood, faeces, duodenal aspirates \\
Small intestinal bacterial overgrowth & Too important bacterial load in the & Duodenal aspirates \\
Specific bacteria or eukaryotes & small intestine & Disturbances in the gut ecosystem \\
Specific bile acid profiles & Disturbances in the gut ecosystem & Faeces, duodenal and gastric aspirates \\
\hline
\end{tabular}


Fecal bacterial taxa associated with PEE It was shown recently in a pilot study that PEE is accompanied by changes in the fecal microbiota [48]. Further, the fecal microbiota of children with SIBO was also shown to be different $[87,88]$. It is therefore likely that given taxa could be valid biomarkers for PEE. Taxa that show significant association with PEE in a multivariate model, will be assessed for their potential use as biomarkers.

Specific bile acid profiles Bile acids are important in lipid absorption and they also play a major role in shaping the microbiota. In turn, the microbiota converts primary bile acids into secondary bile acids by chemical reactions including dehydroxylation, epimerization, oxidation, esterification, and desulfatation, among others [89]. In a recent study, bile acid profiles in the blood were changed in the context of PEE with overall lower amounts of serum bile acids and a higher proportion of bile acids conjugated with taurine in PEE children compared to their non-PEE controls [90]. It is therefore likely that in the context of PEE fecal bile acid pools are changed as well and might represent a good biomarker for the disease.

\section{Understanding the broader environment of children with PEE}

In both countries, a medical anthropological study is conducted in the recruitment districts to evaluate children's social and environmental living conditions. Using an observation grid, we observe hygienic practices, including hand washing, food preparation and consumption, and water storage. Further, data about the medical history of the child, the mother's pregnancy, child feeding and care practices as well as household characteristics are collected with a standardized questionnaire. The data of these questionnaires will be brought into dialogue with household-level participant-observations. We will use additional medical anthropological methods to produce analyses (semi-structured, open-ended interviews, focus groups, ...) of the children's social relations (with caregivers, other family and neighbors) and economic and environmental conditions (Table 3). This evaluation will contribute to the development of socially appropriate intervention and prevention strategies and tools. Comparing data on risk factors associated with PEE from our two study sites, as well as with published data from other studies, will enable us to generalize the observed risk factors and identify possible interventions to minimize the risk of developing PEE.

\section{Psychomotor development}

Each child included in Madagascar undergoes a psychomotor development evaluation with a specifically adapted version of the Ages and Stages 3 Questionnaire (ASQ3, Ages \& Stages Questionnaires ${ }^{\circ}$, Third Edition (ASQ- $\left.3^{\mathrm{mm}}\right)$, Brookes Publishing Co), capturing a child's development in five different spheres (fine motor, gross motor, communication, problem solving, and personal-social). Trained, local psychologists perform the evaluation. The questionnaire was translated to Malagasy and all items were culturally adapted to the local context. We will correlate gut permeability, local and systemic immune status as well as given microbiota profiles with psychomotor development to find biological patterns that might be associated with the psychomotor delay observed in stunted children/ children suffering of PEE.

\section{Quality control and validation}

The recruitment procedures and laboratory protocols were tested before the start of the full study in a pilot study in Antananarivo, Madagascar (15 children included). Procedures were subsequently reviewed and adapted for the full study. An important component of the Afribiota consortium lies in strengthening the research capacities of younger scientists and of the participating African centers, including the different hospitals. Training sessions for good clinical practices, the different medical procedures performed, anthropological and child development techniques as well as of the laboratory techniques were performed in Madagascar and in the Central African Republic prior to the activities. Data management is harmonized between the two study sites and quality control missions took place in both study sites at regular intervals to assess harmonization of laboratory and clinical protocols and control quality of the activities performed. Data is entered in double and controlled by an external data manager.

\section{Statistical considerations Sample size}

To answer all primary and secondary objectives the sample size is of 460 children per country (100 moderately and 100 severely stunted children and 260 non-stunted controls).

For the primary objective, the assessement of the gut ecosystem in the context of stunting and PEE, based on earlier microbiota studies of stunting [91], we estimate to need at least 100 samples per category (non-stunted, moderately or severely stunted) and per country (convenience sampling). Secondary objectives of AFRIBIOTA include the validation of candidate biomarkers for PEE. Sample size for this secondary objective was calculated based on the formula provided by Beam et al. [92] for matched-groups diagnostic study. Assuming a sensitivity and specificity of $80 \%$ for the candidate biomarker, respectively (the sensitivity and specificity of the imperfect reference test were estimated to be respectively 90 and $80 \%$ ), with a power of $80 \%$ a probability of disagreement 
Table 3 Aspects of PEE and stunting studied by the AFRIBIOTA study group

\begin{tabular}{|c|c|c|}
\hline Aspect addressed & Reasoning & Methods used \\
\hline $\begin{array}{l}\text { Social relations, } \\
\text { political and } \\
\text { economic } \\
\text { conditions of } \\
\text { children }\end{array}$ & $\begin{array}{l}\text { Stunting and PEE are linked to } \\
\text { poverty. Specific political } \\
\text { economic conditions and } \\
\text { social relations appear to be } \\
\text { drivers of these two } \\
\text { syndromes. }\end{array}$ & $\begin{array}{l}\text { Participant-observations } \\
\text { Open-ended interviews focusing on life } \\
\text { histories, family histories, specific } \\
\text { practices of social interactions, hygiene } \\
\text { and feeding of children } \\
\text { GPS mapping of major points in } \\
\text { neighborhoods (food, contamination, } \\
\text { play areas, waste disposal, etc.) }\end{array}$ \\
\hline Risk factors & $\begin{array}{l}\text { To date, very little is known } \\
\text { about the actual risk factors } \\
\text { for PEE, a fact that hampers } \\
\text { developing evidence-based } \\
\text { prevention strategies. }\end{array}$ & $\begin{array}{l}\text { Standardized questionnaire about the } \\
\text { general health status of children, } \\
\text { nutrition, family composition, hygiene } \\
\text { and mother's pregnancy } \\
\text { Biological data on micronutrient } \\
\text { deficiencies, inflammation, parasite load }\end{array}$ \\
\hline
\end{tabular}

Diagnostic test To date, the reference test for PEE, the lactitol-mannitol gut permeability test, is difficult and costly to perform in lowincome settings. Further, gut permeability is a non-specific aspect of any inflammatory disease of the intestine. Efforts are therefore needed as to find other, more specific and easier to use biomarkers of the syndrome. The lactitolmannitol gut permeability test is therefore an imperfect test.
Measurement of a given set of nine different biomarkers Sensitivity/Specificity testing against the reference test and latent model of the different markers.

\begin{tabular}{|c|c|}
\hline Study site & Statistical considerations \\
\hline Bangui \& Antananarivo & $\begin{array}{l}30 \text { families with a stunted } \\
\text { child/ child with PEE and } 30 \\
\text { families with a non-stunted } \\
\text { child per country or until } \\
\text { exhaustion. } \\
\text { Data analysis using "grounded } \\
\text { theory" approach }\end{array}$ \\
\hline Bangui \& Antananarivo & $\begin{array}{l}\text { Hypothesizing a PEE } \\
\text { prevalence of } 75 \% \text { in controls } \\
{[57,80] \text { and } 85 \% \text { in cases, to }} \\
\text { show an odds ratio of } 4.8 \text { a } \\
\text { power of } 80 \% \text { and a two- } \\
\text { sided a }=0.05 \text {, an expected } \\
\text { proportion of exposed con- } \\
\text { trols of } 32 \% \text {, a sample size of } \\
30 \text { stunted children and } 100 \\
\text { non-stunted controls is } \\
\text { needed. Accounting for } 10 \% \\
\text { of secondary exclusion, the re- } \\
\text { quired sample size is } 34 \\
\text { stunted children and } 111 \text { non- } \\
\text { stunted control children. }\end{array}$ \\
\hline
\end{tabular}

Bangui \& Antananarivo Sample size was calculated based on the formula provided by Beam et al. [92] for matched-groups diagnostic study. Assuming a sensitivity and specificity of $80 \%$ for the candidate biomarker, respectively (the sensitivity and specificity of the imperfect reference test were estimated to be respectively 90 and $80 \%$ ), with a power of $80 \%$, a probability of disagreement of 0.18 between the two test, an assumed secondary exclusion of $10 \%$, the total estimated sample size is of 128 children, 64 with PEE and 64 without PEE. With an estimated PEE prevalence of $85 \%$ among the stunted children and $75 \%$ among the non-stunted controls [80], 75 stunted children and 256 non-stunted controls have to be included, hence a total of 331 children.

qPCR on a given list of enteric pathogens (bacteria, viruses and parasites)

Microscopy for parasites
Bangui \& Antananarivo Based on earlier studies in Antananarivo [103] and Bangui $[104,105]$ we assume a prevalence of roughly 10\% of any asymptomatic microorganism carriage, among children. To show an odds ratio of 3 between stunting and any asymptomatic pathogen carriage, with an asymptomatic pathogen carriage prevalence of $10 \%$ in non- stunted children [105], a power of $80 \%$ and a twosided $a=0.05$, a sample size of 97 stunted children and 97 non-stunted controls are to be 
Table 3 Aspects of PEE and stunting studied by the AFRIBIOTA study group (Continued)

\begin{tabular}{|c|c|c|c|}
\hline Aspect addressed & Methods used & Study site & Statistical considerations \\
\hline & $\begin{array}{l}\text { enteropathogen carriage and } \\
\text { stunting, which likely is medi- } \\
\text { ated through systemic inflam- } \\
\text { mation [100]. It is likely that } \\
\text { other pathogens might also } \\
\text { contribute to PEE in subclinical } \\
\text { infections. }\end{array}$ & & $\begin{array}{l}\text { recruited. To show an odds ra- } \\
\text { tio of } 3 \text { between the carriage } \\
\text { of a given parasite and PEE, } \\
\text { with a pathogen prevalence } \\
\text { of } 10 \% \text { in non-PEE children, a } \\
\text { power of } 80 \% \text { and a two- } \\
\text { sided a }=0.05 \text {, a sample size } \\
\text { of } 97 \text { PEE children and } 97 \\
\text { non-PEE controls are to be re- } \\
\text { cruited. Assuming a PEE preva- } \\
\text { lence of } 85 \% \text { among the } \\
\text { stunted children and } 75 \% \\
\text { among the non-stunted con- } \\
\text { trols [80], } 115 \text { stunted children } \\
\text { and } 380 \text { non-stunted controls } \\
\text { are to be recruited to assess } \\
\text { the association between nutri- } \\
\text { tional status and PEE. With a } \\
\text { secondary exclusion of } 10 \% \text {, } \\
\text { this sums to a total of } 475 \\
\text { non-stunted children and } 144 \\
\text { stunted children for each } \\
\text { country. The analysis will be } \\
\text { performed pooled on both } \\
\text { countries as to have enough } \\
\text { sample size. }\end{array}$ \\
\hline
\end{tabular}

Small intestinal Impaired small intestinal

bacterial barrier functions - possibly overgrowth (SIBO)

Microbial composition of the gastrointestinal tract (primary objective)

Bile salt profiles also impaired digestive and nutrient transport functions seem to be largely caused by the stable constitution of small intestinal bacteria overgrowth (SIBO) $[50,106]$ causing local and systemic endotoxemia, thus excessive local and systemic inflammation [83]. SIBO is prevalent in shanty towns in many places $[50,83,107,108]$ and it is therefore likely that $\mathrm{SIBO}$ might have a role in PEE.

It has long been speculated that the microbiota might be changed in PEE. However, to date, only a single study in fecal samples was performed, showing changes in the gut microbiota of PEE children compared to their healthy controls [48]. One of the strengths of AFRIBIOTA is its capacity to collect samples in their most relevant location, particularly the collection of duodenal fluid in affected children, which will allow studying the microbiota composition at the location where disease takes place.

Primary bile acids are crucial players in fat absorption. They are transformed into secondary bile acids by the resident gut microbiota. Bile acids are shaping the microbiota by promoting the
Culture of duodenal samples ( $\mathrm{SIBO}>$

$10^{5}$ bacteria/ml of aspirate)

Amplicon sequencing

(16S, 18S, ITS)

IgA targeted bacterial fraction (BugFacs)

Metagenomics
Bangui \& Antananarivo

SIBO analysis can, for ethical reasons, only be performed on stunted children. In the context of this study, 400 stunted children (200 severely stunted and 200 moderately stunted) will be recruited and aspirated. We therefore could not estimate a sample size, but will analyze all collected samples and compare the moderately to the severely malnourished children estimating the power retrospectively (exploratory analysis):

Bangui \& Antananarivo We estimate at least 100 samples per categories and per country are required (effect size unknown, convenience sampling).
Mass spectrometry analysis 
Table 3 Aspects of PEE and stunting studied by the AFRIBIOTA study group (Continued)

\begin{tabular}{|c|c|c|c|c|}
\hline Aspect addressed & Reasoning & Methods used & Study site & Statistical considerations \\
\hline & $\begin{array}{l}\text { growth of bile acid- } \\
\text { metabolizing bacteria and by } \\
\text { inhibiting the growth of bile- } \\
\text { sensitive bacteria. In a recent } \\
\text { study, serum bile acid profiles } \\
\text { were changed in PEE children } \\
\text { [90]. }\end{array}$ & & & \\
\hline $\begin{array}{l}\text { Mucosal } \\
\text { immune system }\end{array}$ & $\begin{array}{l}\text { To date, while it is increasingly } \\
\text { clear that mucosal immune } \\
\text { dysfunction is linked to } \\
\text { stunted growth [109], there is } \\
\text { little knowledge on how PEE } \\
\text { affects the immune system of } \\
\text { the small intestine. Campbell } \\
\text { et al. showed that PEE leads } \\
\text { to an increased presence of T- } \\
\text { cells in the lamina propria and } \\
\text { the epithelium of the small in- } \\
\text { testine of children with PEE } \\
\text { [45, } 46] \text {. Brown et al. showed } \\
\text { that in a weaned mouse } \\
\text { model for PEE, the presence } \\
\text { of NK T cells in the gut was in- } \\
\text { creased [26]. In humans, it is } \\
\text { highly challenging to analyze } \\
\text { the mucosal immune system. } \\
\text { As specific immune cells re- } \\
\text { lease specific cytokines, we } \\
\text { will assess the presence or ab- } \\
\text { sence of individual cytokines. }\end{array}$ & $\begin{array}{l}\text { Cytokine/Chemokines/Growth } \\
\text { Hormone profiling } \\
\text { Immunoglobulin profiling }\end{array}$ & Bangui \& Antananarivo & $\begin{array}{l}\text { We estimate at least } 100 \\
\text { samples per categories and } \\
\text { per country are required } \\
\text { (effect size unknown, } \\
\text { convenience sampling). }\end{array}$ \\
\hline $\begin{array}{l}\text { Systemic } \\
\text { immune system }\end{array}$ & $\begin{array}{l}\text { In the context of chronic } \\
\text { enteropathy, the ratio of } \\
\text { circulating } T_{H} 17 \text { to } T_{\text {reg }} \text { cells is } \\
\text { increased [109, } 110] \text {. To date, } \\
\text { nothing is known about the } \\
\text { circulating cell populations in } \\
\text { PEE. We therefore analyze the } \\
\text { circulating cell populations of } \\
\text { children with chronic } \\
\text { undernutrition and/or PEE. We } \\
\text { will use five eight-color anti- } \\
\text { body panels as well as cyto- } \\
\text { kine and immunoglobulin } \\
\text { profiling in order to quantify } \\
\text { and characterize the major } \\
\text { leukocyte populations and } \\
\text { their secreted immune } \\
\text { molecules. }\end{array}$ & $\begin{array}{l}\text { Cytokine/Chemokines/Growth hormone } \\
\text { profiling } \\
\text { Immunoglobulin profiling } \\
\text { Flow cytometry (B-cells, NK-cells, mono- } \\
\text { cytes and the different subsets of CD4+ } \\
\text { T-cells }\left(T_{H} 1, T_{H} 2, T_{H} 17 \text { and } T_{\text {reg }} \text { ) [68]. }\right.\end{array}$ & $\begin{array}{l}\text { Bangui (cytokine/ } \\
\text { immunoglobulin } \\
\text { profiling) \& } \\
\text { Antananarivo (cytokine/ } \\
\text { immunoglobulin } \\
\text { profiling and flow } \\
\text { cytometry) }\end{array}$ & $\begin{array}{l}\text { We estimate at least } 100 \\
\text { samples per categories and } \\
\text { per country are required } \\
\text { (effect size unknown, } \\
\text { convenience sampling). }\end{array}$ \\
\hline $\begin{array}{l}\text { Mounting of } \\
\text { immune } \\
\text { responses }\end{array}$ & $\begin{array}{l}\text { Vaccines are performing less } \\
\text { well in the developing world } \\
\text { than in industrialized countries } \\
\text { [59]. We hypothesize that this } \\
\text { is due to changes in immune }\end{array}$ & $\begin{array}{l}\text { TruCulture system (Myriad)/ Cytokine/ } \\
\text { Chemokines/Growth hormone profiling } \\
\text { [69] }\end{array}$ & Antananarivo & $\begin{array}{l}\text { We estimate at least } 100 \\
\text { samples per categories and } \\
\text { per country are required } \\
\text { (effect size unknown, } \\
\text { convenience sampling). }\end{array}$ \\
\hline
\end{tabular}
chis and abrogated immune responses as a result of PEE, an association that was previously shown in a few studies $[55,93,110,111]$. In low-income settings, there is widespread absence of trustworthy vaccine records. Therefore, we aim at using an alternative approach, the TruCulture stimulation system (Myriad). This allows investigating the immune response of children in vitro [69]. Stimuli

Cytokine/Chemokines/Growth hormone Bangui (cytokine/ immunoglobulin profiling) \&

immunoglobulin profiling and flow cytometry) categories and per country are required (effect size unknown, convenience sampling). (effect size unknown, convenience sampling). 
Table 3 Aspects of PEE and stunting studied by the AFRIBIOTA study group (Continued)

\begin{tabular}{|c|c|c|c|c|}
\hline Aspect addressed & Reasoning & Methods used & Study site & Statistical considerations \\
\hline & $\begin{array}{l}\text { selected include LPS (gram } \\
\text { negative bacteria), Poly I:C } \\
\text { (double stranded RNA viruses) } \\
\text { and staphylococcal entero- } \\
\text { toxin B (SEB) (T-cells). These } \\
\text { stimuli were selected as they } \\
\text { represent the two groups of } \\
\text { pathogens that cause the } \\
\text { most orally contracted infec- } \\
\text { tions in small children and tar- } \\
\text { get the T-cell response } \\
\text { implicated in PEE pathophysi- } \\
\text { ology }[26,46] \text {. }\end{array}$ & & & \\
\hline $\begin{array}{l}\text { Psychomotor } \\
\text { development of } \\
\text { children }\end{array}$ & $\begin{array}{l}\text { Changes in the microbiota } \\
\text { and its metabolites have been } \\
\text { associated since several years } \\
\text { with brain development ("gut- } \\
\text { brain axis") [112]. Recent } \\
\text { reports also reported helminth } \\
\text { carriage and associated } \\
\text { microbiota changes as one of } \\
\text { the risk factors of delayed } \\
\text { psychomotor development } \\
\text { [113]. Considering the role } \\
\text { these entities play in PEE, it is } \\
\text { therefore likely that PEE is } \\
\text { associated with psychomotor } \\
\text { delays [114]. }\end{array}$ & $\begin{array}{l}\text { Adapted version of } \\
\text { the ASQ3 test }\end{array}$ & Antananarivo & $\begin{array}{l}\text { For the psychometric analysis } \\
\text { internal consistency } \\
\text { (Cronbach's alpha), test-retest, } \\
\text { and inter-rater (Kappa statistics } \\
\text { with expert child develop- } \\
\text { ment specialist) are per- } \\
\text { formed. Validity of the tool is } \\
\text { measured using the Pearson } \\
\text { product moment test and fac- } \\
\text { tor analysis (FA). } \\
\text { For association with PEE, we } \\
\text { estimate to required at least } \\
100 \text { samples per category } \\
\text { (effect size unknown) }\end{array}$ \\
\hline
\end{tabular}

of 0.18 between the two tests, an assumed secondary exclusion of $10 \%$, the total estimated sample size is of 128 children, 64 with PEE and 64 without PEE. With an estimated PEE prevalence of $85 \%$ among the stunted children and $75 \%$ among the non-stunted controls [80], 75 stunted children and 256 non-stunted controls have to be included, hence a total of 331 children.). This sample size will also allow identifying risk factors associated with stunting and PEE with an odds ratio of at least 4.8 as well as performing all other secondary objectives (see Table 3 for a detailed description of the statistical calculation of the different planned analyses).

\section{Definition of PEE}

Initially, gut permeability (lactitol-manitol test) will be used as reference test, as it has been widely used in the literature for defining the syndrome [80]. Each marker will then be compared to the reference test. A second analysis will be performed without using the reference test, considering that all markers have the same weight (latent class analysis model). From these results a reference composite score will be elaborated. PEE will be defined throughout AFRIBIOTA using the lactitol-mannitol value as well as the new composite score.

\section{Discussion}

Despite its broad recognition as a major global health problem, we still know little about the pathogenic mechanisms associated with PEE. It is unlikely that any significant progress will be made towards controlling this syndrome without a clearer understanding of the molecular mechanisms underlying it.

PEE has been studied in the last few years by several groups, including the MAL-ED [49], PROVIDE [93] and SHINE [58] consortia, focusing mainly on very young children ("first 1,000 days"). The first 1000 days have been associated with the most dramatic effect on linear growth delay [94]. Given the complex interactions taking place in undernutrition it is crucial to analyze the syndrome in different countries and in different age groups in order to generalize observations. In AFRIBIOTA, the age range of children included is outside the so-called "first 1000 days". There are several reasons for this: firstly, composition is highly dynamic and diverse in the first 2 years of life ([95], reviewed in [96, 97]), making it difficult to generalize observed phenotypes in a cross-sectional study. At 2-3 years of age, the microbiota stabilizes and hence makes integration with pathophysiological changes more robust. Secondly, while most of the linear growth delay was indeed shown to be acquired in the first 2 years of live, several organs and physiological functions still develop after this initial period, notably the immune system, cognitive functions and several important organs [98]. Chronic undernutrition and stunting beyond the first 1000 days still has a major effect on healthy child growth and linear and psychomotor catch-up growth is to some extent still possible [99]. Studying and treating PEE in children after age 2 
therefore is likewise of concern to assure healthy growth. Further, there are practical and ethical issues involved which constrained our study to only include children $>2$ years of age. Older and hence taller children allow also collecting a larger volume of blood, which allows testing more factors simultaneously.

The MAL-ED consortium was able to shed some light on the pathophysiological mechanisms underlying PEE in children aged $0-2$ years $[48,100]$ and the same consortium as well as the PROVIDE consortium also started comparing and validating other biomarkers for PEE than the actual reference test, the lactitol-mannitol test $[52,101]$. With PEE being so poorly characterized, it is likely that different sub-forms of the disease exist, some leading to bacterial translocation and systemic inflammation, while others lead only to local inflammation in the gut mucosa. The etiologies underlying the syndrome might also vary according to a child's age, nutritional status or living environment. It is therefore crucial to study PEE in different settings in order to capture the complexity of the disease. Furthermore, additional insights are needed into the pathophysiological mechanisms of this syndrome.

AFRIBIOTA, to the best of our knowledge, is the first study aimed at describing the microbiota of stunted children and children with PEE in its most relevant place: the small intestine. This makes it a very valuable addition to the existing studies. Another asset of the study is its geographical location, describing phenotypes in children where, thus far, no studies on the microbiota of healthy or diseased children have been performed. This will allow a comparison of the results of the two countries with each other as well as with other published studies, hence delineating pathophysiological mechanisms and risk factors which are either conserved between different study sites, or which might be specific for a given region ("regional pathophysiological changes").

AFRIBIOTA does have some limitations- importantly, it is a cross-sectional rather than a longitudinal study. This choice, mainly due to financial constraints, will only allow establishing associations but not causality. Nevertheless, we will include almost 1000 children from two distinct countries and will be able to integrate many different aspects of the syndrome in each child. Further, AFRIBIOTA will also generate basic microbiological data and a biobank, which will allow experimental validation of causality in animal models. We hypothesize that, in stunting and PEE, the whole microbial community rather than just isolated members might contribute to morbidity ("ecological Koch's postulates", reviewed in [102]). Therefore, causality can only be experimentally proven by using human samples. The causative role of dysbiotic communities on health can be tested by transplanting these communities into germfree animals, hence isolating the effect of the dysbiosis from other potentially cofounding factors, including social or environmental risk factors. The biobank established in the context of AFRIBIOTA will therefore open the way for targeted, mechanistic animal studies on stunting and PEE.

Through its interdisciplinary nature, AFRIBIOTA has the potential to profoundly change our knowledge about the intestinal ecology of children affected by stunting and PEE as well as the social and biological causes and consequences of these two syndromes. This will help to establish relevant prevention and interventions strategies, for example by targeting a specific behavior or by using probiotics or specific metabolites to treat the syndrome. Ultimately, improved prevention and treatment of PEE is essential to the growth and development of young children around the world.

\section{Abbreviations}

ASQ: Ages-and-stages questionnaire; CAR: Central African Republic; CCTIRS: Comité consultatif sur le traitement de l'information en matière de recherche dans le domaine de la santé; CNIL: Commission Nationale de I'Informatique et des Liberté; CPB: Centre Pédiatrique de Bangui; CRF: Case report form (cahiers d'observation); CRP: C reactive protein; CSMI: Centre de Santé Maternelle et Infantile de Tsaralalàna; CSP: Code de Santé Publique; EAEC: Enteroaggregative E. coli (E. coli enteroaggregatif); EIGI: Effet Indésirable Grave Inattendu; EPEC: Enteropathogenic E. coli (E. coli enteropathogène); ETEC: Enterotoxic E. coli (E. coli enterotoxique); FACS: Fluorescence-assisted cell sorting; HJRA: Hôpital Joseph Ravoahangy Andrianavalona; HMET: Hôpital Mère Enfant de Tsaralalàna;

Ig: Immunoglobulin; MUAC: Middle-upper arm circumference; PEE: Pediatric environmental enteropathy; qPCR: Quantitative polymerase chain reaction; SIBO: Small intestinal bacterial overgrowth; sp.: Species; UNICEF: United Nations International Children's Emergency Fund; WAZ: Weight-for-Age zscore; WHO: World Health Organization; WHZ: Weight-for-Height z-score

\section{Acknowledgements}

The authors wish to thank all participating families, the AFRIBIOTA Consortium, including all field workers, laboratory engineers, technicians, administrative support persons, doctors and nurses, the participating hospitals in Bangui and Antananarivo (Complexe Pédiatrique de Bangui, Centre Hospitalier Universitaire Mère-Enfant de Tsaralalàna (CHUMET), Centre Hospitalier Universitaire Joseph Ravoahangy Andrianavalona (CHUJRA) and Centre de Santé Maternelle et Infantile de Tsaralalàna), the Office National de Nutrition de Madagascar and the Office Régional de Nutrition Analamanga, the Direction de Lutte contre les Infections Sexuellement Transmissibles de Madagascar, the nutrition section of UNICEF in Bangui, Central African Republic, the local health centers in Bangui (St. Joseph de Galabadja, Centre de Santé de Pétévo and Centre de Santé de St. Paul) and in Antananarivo (Centre de Santé d'Ankasina et Centre de Santé d' Andranomanalina Isotry) as well as the community health workers and administrative authorities in the corresponding arrondissements and quartiers. We also wish to than the Institut Pasteur, the Institut Pasteur de Madagascar and the Institut Pasteur de Bangui for their continuous support. The authors wish to thank the Centre de Recherche Translationelle and the Direction Internationale of the Institut Pasteur, especially Paméla Palvadeau, Jane Lynda Deuve, Cécile Artaud, Nathalie Jolly for precious help in setting-up and steering the AFRIBIOTA project. They especially wish to thank Prof. Jean-Louis Demarquez for teaching the local teams in Antananarivo and Bangui the technique of aspirating duodenal fluid and for precious help in validating the aspirations (radiology, pHmetry, ...). The AFRIBIOTA project is supported by a steering committee with the following members: Philippe Sansonetti, Pascale Vonaesch, Rindra Randremanana, Mahehinasy Rakotondrainipiana, JeanChrysostome Gody, Serge Ghislain Djorie, Tamara Giles-Vernick, Jean-Marc Collard, Alain-Berlioz Arthaud (replacing Pierre-Alain Rubbo as from January 2018), Maria Doria, Inès Vigan-Womas, Emna Atchouri and Jane Deuve. A special thank you to the members of the Scientific Advisory Board of AFRIBIOTA, Marcel Tanner, Valerie Curtis, Françoise Ntoumi, Holy Raobelina, 
Andrew Macpherson, David Cohen and Joel Doré, who were decisive in putting AFRIBIOTA on its rails, helped frame the concept about PEE depicted in Fig. 1 and were a constant source of advise, ideas and inspiration. AFRIBIOTA Investigators (Group authorship in alphabetical order): Emilson Jean Andriatahirintsoa, Centre Hospitalier Universitaire Mère Enfant de Tsaralalana, Antananarivo, Madagascar

Laurence Barbot-Trystram, Hôpital Pitié-Salpêtrière, Paris, France Robert Barouki, Hôpital Necker- Enfants maladies, Paris, France Alexandra Bastaraud, Institut Pasteur de Madagascar, Antananarivo, Madagascar Jean-Marc Collard, Institut Pasteur de Madagascar, Antananarivo, Madagascar Maria Doria, Institut Pasteur, Paris, France

Darragh Duffy, Institut Pasteur, Paris, France

Aurélie Etienne, Institut Pasteur, Paris, France/ Institut Pasteur de Madagascar, Madagascar

B. Brett Finlay, University of British Columbia, Vancouver, Canada Serge Ghislain Djorie, Institut Pasteur de Bangui, Bangui, Central African Republic

Tamara Giles-Vernick, Institut Pasteur, Paris, France

Bolmbaye Privat Gondje, Complexe Pédiatrique de Bangui, Bangui, Central African Republic

Jean-Chrysostome Gody, Complexe Pédiatrique de Bangui, Bangui, Central African Republic

Milena Hasan, Institut Pasteur, Paris, France

Jean-Michel Héraud, Institut Pasteur de Madagascar, Antananarivo,

Madagascar

François Huetz, Institut Pasteur, Paris, France

Francis Allan Hunald, Centre Hospitalier Universitaire Joseph Ravoahangy

Andrianavalona (CHU-JRA), Antananarivo, Madagascar

Nathalie Kapel, Hôpital Pitié-Salpêtrière, Paris, France

Jean-Pierre Lombart, Institut Pasteur de Bangui, Bangui, Central African Republic

Alexandre Manirakiza, Institut Pasteur de Bangui, Bangui, Central African Republic

Synthia Nazita Nigatoloum, Complexe Pédiatrique de Bangui, Bangui, Central African Republic

Sophie Novault, Institut Pasteur, Paris, France

Laura Wegener Parfrey, University of British Columbia, Vancouver, Canada

Lisette Raharimalala, Centre social Materno-Infantile, Tsaralalana,

Antananarivo, Madagascar

Maheninasy Rakotondrainipiana, Institut Pasteur de Madagascar,

Antananarivo, Madagascar

Rindra Randremanana, Institut Pasteur de Madagascar, Antananarivo, Madagascar

Harifetra Mamy Richard Randriamizao, Centre Hospitalier Universitaire Joseph

Ravoahangy Andrianavalona (CHU-JRA), Antananarivo, Madagascar

Frédérique Randrianirina, Institut Pasteur de Madagascar, Antananarivo,

Madagascar

Harifetra Mamy Richard Randriamizao

Annick Robinson, Centre Hospitalier Universitaire Mère Enfant de Tsaralalana, Antananarivo, Madagascar

Pierre-Alain Rubbo, Institut Pasteur de Bangui, Bangui, République Centrafricaine

Philippe Sansonetti, Institut Pasteur, Paris, France

Laura Schaeffer, Institut Pasteur, Paris, France

Ionela Gouandjika-Vassilache, Instiut Pasteur de Bangui, Bangui, République Centrafricaine

Pascale Vonaesch, Institut Pasteur, Paris, France

Sonia Sandrine Vondo, Complexe Pédiatrique de Bangui, Bangui, Central

African Republic

Inès Vigan-Womas, Institut Pasteur de Madagascar, Antananarivo, Madagascar

\section{Funding}

This project is funded by the Total Foundation, Institut Pasteur, Odyssey ReInsurance company, Pasteur Foundation Switzerland as well as the Nutricia Research Foundation. PV was supported by an Early.Postdoc.Mobility and Advanced.Postdoc. Mobility Fellowship from the Swiss National Science Foundation, a Roux-Cantarini Fellowship and a L'Oréal-UNESCO for Women in Science France Fellowship. PJS is a HHMI Senior Foreign Scholar and CIFAR scholar in the human microbiome consortium. Work in BBF's group is supported by the Canadian Institute for Health Research. The funders had no role in study design or collection, analysis, and interpretation of data and in writing this manuscript.

\section{Availability of data and materials}

Data sharing is not applicable to this article as no datasets were generated or analysed during the current study. The data underlying the research results will be made publicly available upon publication of the respective analyses.

\section{Authors' contributions}

PV co-initiated the research, co-designed the initial study protocol, cocoordinated the project, wrote the reglementary documents, co-designed the epidemiological, microbiological and immunological analyses and wrote the initial manuscript draft. PJS co-initiated the research, co-designed the initial study protocol, co-coordinated the project, co-designed the microbiological analyses and directed writing of the first manuscript draft. MV codesigned the epidemiological analyses and participated in the initial study protocol design. RR co-designed the epidemiological analyses and provided text elements for the manuscript. JCG contributed to the design of the epidemiological analyses and clinical aspects of the study. JMC contributed to the design of the microbiological analyses and provided text elements for the manuscript. TGV designed the anthropological approach and provided text elements for the manuscript. MD designed the child development analyses and provided text elements for the manuscript. IWW, DD and MH contributed to the design of the immunological analyses. PAR contributed to the design of the microbiological analyses. AM contributed to the design of the epidemiological analyses. AE participated in setting-up the project in Madagascar and contributed to the writing of reglementary documents and clinical procedures. EJA contributed to the clinical procedures. NK contributed to the design of the biomarker analysis. EB, KEH, BBF and LWP contributed to the design of the metabolomics and metataxonomic analyses, respectively. FAH and $A R$ contributed to the design of the clinical aspects of the study. All authors contributed to refine and amend the initial protocol to its actual form. All authors read, edited and approved the final version of the manuscript and consented to its publication.

\section{Ethics approval and consent to participate}

The study protocol for AFRIBIOTA has been approved by the Institutional Review Board of the Institut Pasteur (2016-06/IRB) and the National Ethical Review Boards of Madagascar (55/MSANP/CE, May 19th 2015) and the Central African Republic (173/UB/FACSS/CSCVPER/16). All participants received oral and written information about the study and the legal representatives of the children provided written consent to participate in the study. Data sharing is not applicable to this article as no datasets were generated or analysed during the current study. A copy of the written consent is available for review by the Editor of this journal.

\section{Consent for publication}

Not applicable

\section{Competing interests}

Pierre-Alain Rubbo is the Founding Chief Executive Officer and one of the shareholders, of the start-up company Omunis. Omunis did not provide any financial support for AFRIBIOTA and did not have any role in the study design, data collection and analysis, decision to publish or preparation of the manuscript. The other authors declare no competing interests.

\section{Publisher's Note}

Springer Nature remains neutral with regard to jurisdictional claims in published maps and institutional affiliations.

\section{Author details}

${ }^{1}$ Unité de Pathogénie Microbienne Moléculaire, Institut Pasteur, 28 Rue du Dr. Roux, 75015 Paris, France. ' Unité d'Epidémiologie et de Recherche Clinique, Institut Pasteur de Madagascar, BP 1274 Ambatofotsikely, Avaradoha, 101 Antananarivo, Madagascar. ${ }^{3}$ Centre Pédiatrique de Bangui, Avenue de I'Indépendance, Bangui, Central African Republic. ${ }^{4}$ Unité de Bactériologie Expérimentale, Institut Pasteur de Madagascar, BP 1274 Ambatofotsikely, Avaradoha, 101 Antananarivo, Madagascar. ${ }^{5}$ Unité d'Epidémiologie des Maladies Emergentes, Institut Pasteur, 28 Rue du Dr. Roux, 75015 Paris, France. ${ }^{6}$ Unité d'Immunologie des Maladies Infectieuses, Institut Pasteur de Madagascar, BP 1274 Ambatofotsikely, Avaradoha, 101 Antananarivo, Madagascar. 'Laboratoire d'Analyses Médicales, Institut Pasteur de Bangui, Avenue de l'Indépendance, Bangui, Central African Republic. ${ }^{8}$ Centre Hospitalier Universitaire Mère-Enfant de Tsaralalàna (CHUMET), rue 
Patrice Lumumba, Tsaralalàna, 101 Antananarivo, Madagascar. ${ }^{9}$ Laboratoire de Coprologie Fonctionnelle, Hôpital Pitié-Salpêtrière, 47-83 Bd de l'Hôpital, 75013 Paris, France. ${ }^{10}$ Michael Smith Laboratories, University of British Columbia, 2185 East Mall, Vancouver V6T1Z4, Canada. ${ }^{11}$ Unité de la Biologie des Cellules Dendritiques, Institut Pasteur, 25 Rue du Dr. Roux, 75015 Paris, France. ${ }^{12}$ Centre de Recherche Translationnelle, Institut Pasteur, 28 Rue du Dr. Roux, 75015 Paris, France. ${ }^{13}$ Centre Hospitalier Universitaire Joseph Ravoahangy Andrianavalona (CHUJRA), Antananarivo, Madagascar. ${ }^{14}$ Centre Hospitalier Universitaire Mère Enfant de Tsaralalana, Antananarivo, Madagascar. ${ }^{15}$ Unité d'Epidémiologie, Institut Pasteur de Bangui, Avenue de I'Indépendance, Bangui, Central African Republic. ${ }^{16}$ Departments of Botany and Zoology, and Biodiversity Research Centre, University of British Columbia, 3200-6270 University Boulevard, Vancouver V6T1Z4, Canada.

\section{Received: 16 May 2018 Accepted: 21 June 2018} Published online: 19 July 2018

\section{References}

1. Onis M. WHO child growth standards based on length/height, weight and age. Acta Paediatr. 2006;95:76-85. Available from: http://onlinelibrary.wiley. com/doi/10.1111/j.1651-2227.2006.tb02378.x/full

2. Group WMGRS. ... Standards: Head circumference-for-age, arm circumference-for-age, triceps skinfold-for-age and subscapular skinfold-forage: methods and development [Internet]. Geneva: World Health ...; 2007. Available from: http://scholar.google.com/scholar?q=related:slGn-4ubr2QJ: scholar.google.com/\&hl=en\&num=20\&as_sdt=0,5

3. ensomd-2012 IMASIHWIMP, 2013. Enquête nationale sur le suivi des objectifs du millénaire pour le développement à Madagascar. http://www. undp.org/content/dam/madagascar/docs/rapportsUNDP_MDG/doc_OMD/ OMD_5_mg_2013.pdf.

4. Dewey KG, Begum K. Long-term consequences of stunting in early life. Matern Child Nutr. 2011;7:5-18. Available from: http://eutils.ncbi.nlm.nih.gov/entrez/ eutils/elink.fcgi?dbfrom=pubmed\&id=21929633\&retmode=ref\&cmd=prlinks

5. Adair LS. Long-term consequences of nutrition and growth in early childhood and possible preventive interventions. International nutrition: achieving millennium goals and beyond [Internet]. Basel: S. KARGER AG; 2014. p. 111-20. Available from: http://eutils.ncbi.n/m.nih.gov/entrez/eutils/ elink.fcgi?dbfrom=pubmed\&id=24504211\&retmode=ref\&cmd=prlinks

6. Schaible UE, Kaufmann SHE. Malnutrition and infection: complex mechanisms and global impacts. PLoS Med. 2007;4:e115.

7. Wang AZ, Shulman RJ, Crocker AH, Thakwalakwa C, Maleta KM, Devaraj S, et al. A combined intervention of zinc, multiple micronutrients, and Albendazole does not ameliorate environmental enteric dysfunction or stunting in rural Malawian children in a double-blind randomized controlled trial. J Nutr. 2017;147:97-103.

8. de Onis M, Branca F. Childhood stunting: a global perspective. Aguayo VM, Menon P, editors. Matern Child Nutr. 2016;12:12-26. Available from: http:// eutils.ncbi.nlm.nih.gov/entrez/eutils/elink.fcgi?dbfrom=pubmed\&id=271879 07\&retmode $=$ ref\&cmd=prlinks

9. Stewart CP, lannotti L, Dewey KG, Michaelsen KF \& Onyango AW. Contextualising complementary feeding in a broader framework for stunting prevention. Maternal and Child Nutrition. 2013;9(Suppl 2):27-45. available from: http://www.who.int/nutrition/events/2013_ ChildhoodStunting_colloquium_140ct_ConceptualFramework_colour.pdf.

10. Dewey KG, Adu-Afarwuah S. Systematic review of the efficacy and effectiveness of complementary feeding interventions in developing countries. Matern Child Nutr. 2008;4:24-85. Available from: http://eutils.ncbi. nlm.nih.gov/entrez/eutils/elink.fcgi?dbfrom=pubmed\&id=18289157\&ret mode $=$ ref\&cmd $=$ prlinks

11. Lunn PG, Northrop-Clewes CA, Downes RM. Intestinal permeability, mucosal injury, and growth faltering in Gambian infants. Lancet. 1991;338:907-10.

12. Solomons NW. Environmental contamination and chronic inflammation influence human growth potential. J Nutr. 2003;133:1237.

13. McKay S, Gaudier E, Campbell DI, Prentice AM, Albers R. Environmental enteropathy: new targets for nutritional interventions. Int Health. 2010;2:172-80.

14. Gilmartin AA, Petri WA. Exploring the role of environmental enteropathy in malnutrition, infant development and oral vaccine response. Philos Trans $R$ Soc Lond Ser B Biol Sci. 2015;370:20140143.

15. Morita T, Perin J, Oldja L, Biswas S, Sack RB, Ahmed S, et al. Mouthing of soil contaminated objects is associated with environmental enteropathy in young children. Tropical Med Int Health. 2017;22:670-8.
16. George CM, Oldja L, Biswas S, Perin J, Lee GO, Kosek M, et al. Geophagy is associated with environmental enteropathy and stunting in children in rura Bangladesh. Am J Trop Med Hyg. 2015;92:1117-24.

17. Perin J, Thomas A, Oldja L, Ahmed S, Parvin T, Bhuyian SI, et al. Geophagy is associated with growth faltering in children in rural Bangladesh. J Pediatr. 2016;178:34-39.e1.

18. George CM, Oldja L, Biswas S, Perin J, Sack RB, Ahmed S, et al. Unsafe child feces disposal is associated with environmental Enteropathy and impaired growth. J Pediatr. 2016;176:43-9.

19. George CM, Oldja L, Biswas SK, Perin J, Lee GO, Ahmed S, et al. Fecal markers of environmental enteropathy are associated with animal exposure and caregiver hygiene in Bangladesh. Am J Trop Med Hyg. 2015;93:269-75.

20. Watanabe K, Petri WA. Environmental enteropathy: elusive but significant subclinical abnormalities in developing countries. EBioMedicine. 2016;10:25-32.

21. Korpe PS, Petri WA. Environmental enteropathy: critical implications of a poorly understood condition. Trends Mol Med. 2012;18:328-36.

22. Prendergast A, Kelly P. Enteropathies in the developing world: neglected effects on global health. Am J Trop Med Hyg. 2012;86:756-63.

23. Keusch GT, Rosenberg $I H$, Denno DM, Duggan C, Guerrant RL, Lavery JV, et al. Implications of acquired environmental enteric dysfunction for growth and stunting in infants and children living in low- and middle-income countries. Food Nutr Bull. 2013;34:357-64.

24. Prendergast AJ, Humphrey $\mathrm{JH}$. The stunting syndrome in developing countries. Paediatr Int Child Health. 2014;34:250-65. Available from: http://eutils.ncbi.nlm.nih.gov/entrez/eutils/elink.fcgi?dbfrom=pubmed\&id= 25310000\&retmode $=$ ref\& $\mathrm{cmd}=$ prlinks

25. Ahmed T, Auble D, Berkley JA, Black R, Ahern PP, Hossain M, et al. An evolving perspective about the origins of childhood undernutrition and nutritional interventions that includes the gut microbiome. Ann N Y Acad Sci. 2014;1332:22-38.

26. Brown EM, Wlodarska M, Willing BP, Vonaesch P, Han J, Reynolds LA, et al. Diet and specific microbial exposure trigger features of environmental enteropathy in a novel murine model. Nat Commun. 2015;6:7806.

27. Louis-Auguste J, Kelly P. Tropical enteropathies. Curr Gastroenterol Rep. 2017;19:29.

28. Arndt MB, Richardson BA, Ahmed T, Mahfuz M, Haque R, John-Stewart GC, et al. Fecal markers of environmental enteropathy and subsequent growth in Bangladeshi children. Am J Trop Med Hyg. 2016;95:694-701.

29. Harper KM, Mutasa M, Prendergast AJ, Humphrey J, Manges AR. Environmental enteric dysfunction pathways and child stunting: a systematic review. Kosek M, editor. PLoS Negl Trop Dis. 2018;12:e0006205.

30. Kelly P, Menzies I, Crane R, Zulu I, Nickols C, Feakins R, et al. Responses of small intestinal architecture and function over time to environmental factors in a tropical population. Am J Trop Med Hyg. 2004;70:412-9.

31. Kelly P, Besa E, Zyambo K, Louis-Auguste J, Lees J, Banda T, et al. Endomicroscopic and Transcriptomic analysis of impaired barrier function and malabsorption in environmental enteropathy. Petri WA, editor. PLoS Negl Trop Dis. 2016;10:e0004600.

32. Lee GO, McCormick BJJ, Seidman JC, Kosek MN, Haque R, Olortegui MP, et al. Infant nutritional status, feeding practices, enteropathogen exposure, socioeconomic status, and illness are associated with gut barrier function as assessed by the lactulose mannitol test in the MAL-ED birth cohort. Am J Trop Med Hyg. 2017;97:281-90.

33. George CM, Burrowes V, Perin J, Oldja L, Biswas S, Sack D, et al. Enteric infections in young children are associated with environmental enteropathy and impaired growth. Tropical Med Int Health. 2018;23:26-33.

34. Rogawski ET, Guerrant RL, Havt A, Lima IFN, Medeiros PHQS, Seidman JC, et al. Epidemiology of enteroaggregative Escherichia coli infections and associated outcomes in the MAL-ED birth cohort. Baker S, editor. PLoS Negl Trop Dis. 2017;11:e0005798.

35. Steiner TS, Lima AA, Nataro JP, Guerrant RL. Enteroaggregative Escherichia coli produce intestinal inflammation and growth impairment and cause interleukin-8 release from intestinal epithelial cells. J Infect Dis. 1998;177:88-96.

36. Lindenbaum J, Gerson CD, Kent TH. Recovery of small-intestinal structure and function after residence in the tropics. I. Studies in peace corps volunteers. Ann Intern Med. 1971;74:218-22.

37. Gerson CD, Kent TH, Saha JR, Siddiqi N, Lindenbaum J. Recovery of small-intestinal structure and function after residence in the tropics. II Studies in Indians and Pakistanis living in New York City. Ann Intern Med. 1971;75:41-8. 
38. Kau AL, Planer JD, Liu J, Rao S, Yatsunenko T, Trehan I, et al. Functional characterization of IgA-targeted bacterial taxa from undernourished Malawian children that produce diet-dependent enteropathy. Sci Transl Med. 2015;7:276ra24.

39. Blanton LV, Charbonneau MR, Salih T, Barratt MJ, Venkatesh S, Ilkaveya O, et al. Gut bacteria that prevent growth impairments transmitted by microbiota from Fur children. Science. 2016;351:aad3311.

40. Desai HG, Borkar AV, Pathare SM, Dighe PK, Jeejeebhoy KN. "Flat" jejunal mucosa in the tropics. Indian J Med Sci. 1969;23:1-5.

41. Chacko CJ, Paulson KA, Mathan VI, Baker SJ. The villus architecture of the small intestine in the tropics: a necropsy study. J Pathol. 1969;98:146-51.

42. Fagundes-Neto U, Martins MC, Lima FL, Patrício FR, Toledo MR. Asymptomatic environmental enteropathy among slum-dwelling infants. J Am Coll Nutr. 1994;13:51-6.

43. Fagundes-Neto $U$, Kallas MR, Patrício FR. Morphometric study of the small bowel mucosa in infants with diarrhea due to enteropathogenic Escherichia coli strains. Hepato-Gastroenterology. 1997;44:1051-6.

44. Kallas MR, Patrício FR, Fagundes-Neto U. Morphometrics of the small intestine in children with diarrhea due to classical enteropathogenic Escherichia coli and to environmental asymptomatic enteropathy. Rev Assoc Med Bras (1992). 1995:41:162-6.

45. Campbell DI, Murch SH, Elia M, Sullivan PB, Sanyang MS, Jobarteh B, et al. Chronic T cell-mediated enteropathy in rural West African children: relationship with nutritional status and small bowel function. Pediatr Res. 2003;54:306-11.

46. Campbell DI, Elia M, Lunn PG. Growth faltering in rural Gambian infants is associated with impaired small intestinal barrier function, leading to endotoxemia and systemic inflammation. J Nutr. 2003;133:1332-8.

47. Lee GO, Olortegui MP, Salas MS, Yori PP, Trigoso DR, Kosek P, et al. Environmental enteropathy is associated with cardiometabolic risk factors in Peruvian children. J Dev Orig Health Dis. 2017;8:337-48.

48. Ordiz MI, Stephenson K, Agapova S, Wylie KM, Maleta K, Martin J, et al. Environmental enteric dysfunction and the fecal microbiota in Malawian children. Am J Trop Med Hyg. 2017;96:473-6.

49. MAL-ED Network Investigators. The MAL-ED study: a multinational and multidisciplinary approach to understand the relationship between enteric pathogens, malnutrition, gut physiology, physical growth, cognitive development, and immune responses in infants and children up to 2 years of age in resource-poor environments. Clin Infect Dis. 2014;59(Suppl 4): S193-206.

50. Donowitz JR, Haque R, Kirkpatrick BD, Alam M, Lu M, Kabir M, et al. Small intestine bacterial overgrowth and environmental enteropathy in Bangladeshi children. MBio. 2016;7:e02102-15.

51. Lu M, Zhou J, Naylor C, Kirkpatrick BD, Haque R, Petri WA, et al. Application of penalized linear regression methods to the selection of environmental enteropathy biomarkers. Biomark Res. 2017:5:9.

52. Guerrant RL, Leite ÁM, Pinkerton R, Medeiros PHQS, Cavalcante PA, DeBoer $M$, et al. Biomarkers of environmental enteropathy, inflammation, stunting, and impaired growth in children in Northeast Brazil. Weber CR, editor. PLoS ONE. 2016;11:e0158772.

53. Johansson MEV, Gustafsson JK, Holmén-Larsson J, Jabbar KS, Xia L, Xu H, et al. Bacteria penetrate the normally impenetrable inner colon mucus layer in both murine colitis models and patients with ulcerative colitis. Gut. 2014;63:281-91.

54. Sherwood R, Walsham N. Fecal calprotectin in inflammatory bowel disease. Clin Exp Gastroenterol. 2016;9:21-9.

55. Lagos R, Fasano A, Wasserman SS, Prado V, San Martin O, Abrego P, et al. Effect of small bowel bacterial overgrowth on the immunogenicity of single-dose live oral cholera vaccine CVD 103-HgR. J Infect Dis. 1999;180:1709-12.

56. Trehan I, Shulman RJ, Ou C-N, Maleta K, Manary MJ. A randomized, doubleblind, placebo-controlled trial of rifaximin, a nonabsorbable antibiotic, in the treatment of tropical enteropathy. Am J Gastroenterol. 2009;104:2326-33.

57. Galpin L, Manary MJ, Fleming K, Ou C-N, Ashorn P, Shulman RJ. Effect of lactobacillus GG on intestinal integrity in Malawian children at risk of tropical enteropathy. Am J Clin Nutr. 2005;82:1040-5.

58. Sanitation Hygiene Infant Nutrition Efficacy (SHINE) Trial Team, Humphrey JH, Jones AD, Manges A, Mangwadu G, Maluccio JA, et al. The Sanitation Hygiene Infant Nutrition Efficacy (SHINE) Trial: Rationale, Design, and Methods. Clin Infect Dis. 2015;61(Suppl 7):S685-702.

59. Kirkpatrick BD, Colgate ER, Mychaleckyj JC, Haque R, Dickson DM, Carmolli $M P$, et al. The "Performance of Rotavirus and Oral Polio Vaccines in Developing Countries" (PROVIDE) study: description of methods of an interventional study designed to explore complex biologic problems. Am J Trop Med Hyg. 2015;92:744-51.

60. Angelakis E, Armougom F, Carrière F, Bachar D, Laugier R, Lagier J-C, et al. A metagenomic investigation of the duodenal microbiota reveals links with obesity. Covasa M, editor. PLoS ONE. 2015;10:e0137784.

61. Li G, Yang M, Zhou K, Zhang L, Tian L, Lv S, et al. Diversity of duodenal and rectal microbiota in biopsy tissues and luminal contents in healthy volunteers. J Microbiol Biotechnol. 2015;25:1136-45.

62. Hillman ET, Lu H, Yao T, Nakatsu CH. Microbial ecology along the gastrointestinal tract. Microbes Environ. 2017;32:300-13.

63. Sekirov I, Tam NM, Jogova M, Robertson ML, Li Y, Lupp C, et al. Antibioticinduced perturbations of the intestinal microbiota alter host susceptibility to enteric infection. Infect Immun. 2008;76:4726-36.

64. Modi SR, Collins JJ, Relman DA. Antibiotics and the gut microbiota. J Clin Invest. 2014:124:4212-8.

65. Dethlefsen $L$, Huse $S$, Sogin ML, Relman DA. The pervasive effects of an antibiotic on the human gut microbiota, as revealed by deep 165 rRNA sequencing. Eisen JA, editor. PLOS Biol. 2008;6:e280.

66. Hill DA, Hoffmann C, Abt MC, Du Y, Kobuley D, Kirn TJ, et al. Metagenomic analyses reveal antibiotic-induced temporal and spatial changes in intestinal microbiota with associated alterations in immune cell homeostasis. Mucosal Immunol. 2010;3:148-58.

67. Smith MI, Yatsunenko T, Manary MJ, Trehan I, Mkakosya R, Cheng J, et al. Gut microbiomes of Malawian twin pairs discordant for kwashiorkor. Science. 2013;339:548-54.

68. Hasan M, Beitz B, Rouilly V, Libri V, Urrutia A, Duffy D, et al. Semi-automated and standardized cytometric procedures for multi-panel and multi-parametric whole blood immunophenotyping. Clin Immunol. 2015;157:261-76.

69. Duffy D, Rouilly V, Libri V, Hasan M, Beitz B, David M, et al. Functional analysis via standardized whole-blood stimulation systems defines the boundaries of a healthy immune response to complex stimuli. Immunity. 2014;40:436-50.

70. Kalach N, Kapel N, Waligora-Dupriet A-J, Castelain M-C, Cousin MO, Sauvage C, et al. Intestinal permeability and fecal eosinophil-derived neurotoxin are the best diagnosis tools for digestive non-lgE-mediated cow's milk allergy in toddlers. Clin Chem Lab Med. 2013;51:351.

71. Lee GO, Kosek P, Lima AAM, Singh R, Yori PP, Olortegui MP, et al. Lactulose: mannitol diagnostic test by HPLC and LC-MSMS platforms: considerations for field studies of intestinal barrier function and environmental enteropathy. J Pediatr Gastroenterol Nutr. 2014;59:544-50.

72. Weisz AJ, Manary MJ, Stephenson K, Agapova S, Manary FG, Thakwalakwa C, et al. Abnormal gut integrity is associated with reduced linear growth in rural Malawian children. J Pediatr Gastroenterol Nutr. 2012;55:747-50.

73. Macpherson AJ, Geuking MB, Slack E, Hapfelmeier S, McCoy KD. The habitat, double life, citizenship, and forgetfulness of IgA. Immunol Rev. 2012;245:132-46.

74. Maier EA, Weage KJ, Guedes MM, Denson LA, McNeal MM, Bernstein DI, et al. Protein-energy malnutrition alters IgA responses to rotavirus vaccination and infection but does not impair vaccine efficacy in mice. Vaccine. 2013;32:48-53.

75. Wessells KR, Hess SY, Rouamba N, Ouédraogo ZP, Kellogg M, Goto R, et al. Associations between intestinal mucosal function and changes in plasma zinc concentration following zinc supplementation. J Pediatr Gastroenterol Nutr. 2013;57:348-55.

76. Papadia C, Kelly P, Caini S, Corazza GR, Shawa T, Franzè A, et al. Plasma citrulline as a quantitative biomarker of HIV-associated villous atrophy in a tropical enteropathy population. Clin Nutr. 2010;29:795-800.

77. Crenn P, Messing B, Cynober L. Citrulline as a biomarker of intestinal failure due to enterocyte mass reduction. Clin Nutr. 2008;27:328-39.

78. Crenn P, Hanachi M, Neveux N, Cynober L. Circulating citrulline levels: a biomarker for intestinal functionality assessment. Ann Biol Clin (Paris). 2011; 69:513-21.

79. McDonald CM, Manji KP, Gosselin K, Tran H, Liu E, Kisenge R, et al. Elevations in serum anti-flagellin and anti-LPS Igs are related to growth faltering in young Tanzanian children. Am J Clin Nutr. 2016;103:1548-54.

80. Lin A, Arnold BF, Afreen S, Goto R, Huda TMN, Haque R, et al. Household environmental conditions are associated with enteropathy and impaired growth in rural Bangladesh. Am J Trop Med Hyg. 2013;89:130-7.

81. Benzoni N, Korpe P, Thakwalakwa C, Maleta K, Stephenson K, Manary M, et al. Plasma endotoxin core antibody concentration and linear growth are unrelated in rural Malawian children aged 2-5 years. BMC Res Notes. 2015:8:258.

82. Ritchie BK, Brewster DR, Davidson GP, Tran CD, McNeil Y, Hawkes JS, et al. 13C-sucrose breath test: novel use of a noninvasive biomarker of environmental gut health. Pediatrics. 2009;124:620-6. 
83. Reis dos JC, de Morais MB, Oliva CAG, Fagundes-Neto U. Breath hydrogen test in the diagnosis of environmental enteropathy in children living in an urban slum. Dig Dis Sci. 2007;52:1253-8.

84. Reis dos JC, de Morais MB, Fagundes-Neto U. Breath hydrogen test to evaluate lactose absorption and small bowel bacterial overgrowth in children. Arq Gastroenterol. 1999;36:169-76.

85. Ghoshal UC, Ghoshal U, Das K, Misra A. Utility of hydrogen breath tests in diagnosis of small intestinal bacterial overgrowth in malabsorption syndrome and its relationship with oro-cecal transit time. Indian J Gastroenterol. 2006;25:6-10.

86. Chandra S, Dutta U, Noor MT, Taneja N, Kochhar R, Sharma M, et al. Endoscopic jejunal biopsy culture: a simple and effective method to study jejunal microflora. Indian. J Gastroenterol. 2010;29:226-30.

87. Lifschitz C, Sieczkowska A. New insights into the fecal microbiota of children living in a slum: association with small bowel bacterial overgrowth. J Pediatr (Rio J). 2017; https://doi.org/10.1016/j.jped.2017.12.002. [Epub ahead of print]; PMID: 29274895; https://doi.org/10.1016/j.jped.2017.12.002. Accessible at: https://www. sciencedirect.com/science/article/pii/S0021755717311865?via\%3Dihub.

88. Mello CS, Rodrigues MSDC, Filho HB de A, Melli LCFL, Tahan S, Pignatari ACC, et al. Fecal microbiota analysis of children with small intestinal bacterial overgrowth among residents of an urban slum in Brazil. J Pediatr (Rio J). 2017;https://doi.org/10.1016/j.jped.2017.09.003. [Epub ahead of print]. Accessible at: https://www.sciencedirect.com/science/article/pii/S002175571 6303862?via\%3Dihub.

89. Ridlon JM, Kang DJ, Hylemon PB, Bajaj JS. Bile acids and the gut microbiome. Curr Opin Gastroenterol. 2014;30:332-8.

90. Semba RD, Gonzalez-Freire M, Moaddel R, Trehan I, Maleta KM, Khadeer M, et al. Environmental enteric dysfunction is associated with altered bile acid metabolism. J Pediatr Gastroenterol Nutr. 2017;64:536-40

91. Gough EK, Stephens DA, Moodie EEM, Prendergast AJ, Stoltzfus RJ, Humphrey $\mathrm{JH}$, et al. Linear growth faltering in infants is associated with Acidaminococcus sp. and community-level changes in the gut microbiota. Microbiome. 2015;3:24.

92. Beam CA. Strategies for improving power in diagnostic radiology research AJR Am J Roentgenol. 2013;159:631-7.

93. Naylor C, Lu M, Haque R, Mondal D, Buonomo E, Nayak U, et al. Environmental enteropathy, oral vaccine failure and growth faltering in infants in Bangladesh. EBioMedicine. 2015;2:1759-66.

94. Victora CG, Victora CG, de Onis M, de Onis M, Hallal PC, Hallal PC, et al. Worldwide timing of growth faltering: revisiting implications for interventions. Pediatrics. 2010;125:e473-80. Available from: http://eutils.ncbi. nlm.nih.gov/entrez/eutils/elink.fcgi?dbfrom=pubmed\&id=20156903\&ret mode $=$ ref\&cmd $=$ prlinks

95. Yatsunenko T, Rey FE, Manary MJ, Trehan I, Dominguez-Bello MG, Contreras $\mathrm{M}$, et al. Human gut microbiome viewed across age and geography. Nature. 2012;486:222-7.

96. Rodríguez JM, Murphy K, Stanton C, Ross RP, Kober Ol, Juge N, et al. The composition of the gut microbiota throughout life, with an emphasis on early life. Microb Ecol Health Dis. 2015:26:26050.

97. Sanders TAB. Establishing of gut microbiota and bacterial colonisation of the gut in early life. Nutrition and development. West Sussex: Wiley; 2013. p. 116-29.

98. Prentice AM, Ward KA, Goldberg GR, Jarjou LM, Moore SE, Fulford AJ, et al. Critical windows for nutritional interventions against stunting. Am J Clin Nutr. 2013;97:911-8.

99. Georgiadis A, Penny ME. Child undernutrition: opportunities beyond the first 1000 days. Lancet Public Health. 2017;2:e399.

100. Kosek MN, MAL-ED Network Investigators, Bhutta Z, Guerrant R, Houpt E, Kang $G$, et al. Causal pathways from enteropathogens to environmental enteropathy: findings from the MAL-ED birth cohort study. EBioMedicine. 2017;18:109-17. Available from: http://eutils.ncbi. $\mathrm{nlm}$.nih.gov/entrez/eutils/elink.fcgi?dbfrom=pubmed\&id=28396264\&ret mode $=$ ref\&cmd $=$ prlinks

101. Colston JM, Peñataro Yori P, Colantuoni E, Moulton LH, Ambikapathi R, Lee $G$, et al. A methodologic framework for modeling and assessing biomarkers of environmental enteropathy as predictors of growth in infants: an example from a Peruvian birth cohort. Am J Clin Nutr. 2017; 106:245-55.

102. Vonaesch P, Anderson M, Sansonetti PJ. Pathogens, microbiome and the host: emergence of the ecological Koch's postulates. FEMS Microbiol Rev. 2018:454:987.
103. Randremanana RV, Razafindratsimandresy R, Andriatahina $T$, Randriamanantena A, Ravelomanana L, Randrianirina F, et al. Etiologies, risk factors and impact of severe diarrhea in the under-fives in Moramanga and Antananarivo, Madagascar. Huang Y-C, editor. PLoS ONE. 2016;11:e0158862. Available from: http://eutils.ncbi.nlm.nih.gov/ entrez/eutils/elink.fcgi?dbfrom=pubmed\&id=27411101\&retmode=ref\& cmd=prlinks

104. Breurec S, Vanel N, Bata P, Chartier L, Farra A, Favennec L, et al. Etiology and epidemiology of diarrhea in hospitalized children from low income country: a matched case-control study in Central African Republic. Ryan ET, editor. PLoS Negl Trop Dis. 2016;10:e0004283.

105. Vonaesch P, Tondeur L, Breurec S, Bata P, Nguyen LBL, Frank T, et al. Factors associated with stunting in healthy children aged 5 years and less living in Bangui (RCA). Wieringa F, editor. PLoS ONE. 2017;12: e0182363.

106. Donowitz JR, Petri WA. Pediatric small intestine bacterial overgrowth in lowincome countries. Trends Mol Med. 2015:21:6-15.

107. Mello CS. Methane production and small intestinal bacterial overgrowth in children living in a slum. World J Gastroenterol. 2012:18:5932-9.

108. Khin-Maung-U, Bolin TD, Duncombe VM, Myo-Khin, Nyunt-Nyunt-Wai, Pereira SP, et al. Epidemiology of small bowel bacterial overgrowth and rice carbohydrate malabsorption in Burmese (Myanmar) village children. Am J Trop Med Hyg. 1992;47:298-304.

109. Yu J, Ordiz Ml, Stauber J, Shaikh N, Trehan I, Barnell E, et al. Environmental enteric dysfunction includes a broad spectrum of inflammatory responses and epithelial repair processes. Cell Mol Gastroenterol Hepatol. 2016;2:158-174.e1.

110. Parker EP, Ramani S, Lopman BA, Church JA, Iturriza-Gómara M, Prendergast AJ, et al. Causes of impaired oral vaccine efficacy in developing countries. Future Microbiol. 2018:13:97-118.

111. Becker-Dreps S, Vilchez S, Bucardo F, Twitchell E, Choi WS, Hudgens MG et al. The association between fecal biomarkers of environmental enteropathy and rotavirus vaccine response in Nicaraguan infants. Pediatr Infect Dis J. 2017;36:412-6.

112. Oriá RB, Murray-Kolb LE, Scharf RJ, Pendergast LL, Lang DR, Kolling GL, et al. Early-life enteric infections: relation between chronic systemic inflammation and poor cognition in children. Nutr Rev. 2016;74:374-86.

113. Guernier V, Brennan B, Yakob L, Milinovich G, Clements ACA, Soares Magalhaes RJ. Gut microbiota disturbance during helminth infection: can it affect cognition and behaviour of children? BMC Infect Dis. 2017;17:58.

114. Ngure FM, Reid BM, Humphrey JH, Mbuya MN, Pelto G, Stoltzfus RJ. Water, sanitation, and hygiene (WASH), environmental enteropathy, nutrition, and early child development: making the links. Black MM, Dewey KG, editors. Ann N Y Acad Sci. 2014;1308:118-28.

\section{Ready to submit your research? Choose BMC and benefit from:}

- fast, convenient online submission

- thorough peer review by experienced researchers in your field

- rapid publication on acceptance

- support for research data, including large and complex data types

- gold Open Access which fosters wider collaboration and increased citations

- maximum visibility for your research: over $100 \mathrm{M}$ website views per year

At BMC, research is always in progress.

Learn more biomedcentral.com/submissions 